\title{
LA INTEGRACIÓN DE MEDIDAS DE EFICIENCIA ENERGÉTICA EN LA EDIFICACIÓN A LA VISTA DE LOS OBJETIVOS DE LA UE PARA LOS HORIZONTES 2020-2030. LAS REDES DISTRICT HEATING AND COOLING
}

\section{THE INTEGRATION OF ENERGY EFFICIENCY MEASURES IN CONSTRUCTION IN THE CONTEXT OF THE OBJECTIVES OF THE EU'S 2020-2030 HORIZONS: DISTRICT HEATING AND COOLING NETWORKS}

\author{
JUDITH GIFREU FONT \\ Profesora Titular de Derecho Administrativo \\ Universidad Autónoma de Barcelona \\ judith.gifreu@uab.cat
}

Recibido: 16 de agosto de 2018 / Aceptado: 15 de mayo de 2019

RESUMEN: La eficiencia energética forma parte, junto con la reducción de emisiones de gases de efecto invernadero y el fomento de las energías renovables, de los objetivos prioritarios de la política energética de la UE con vistas a garantizar la sostenibilidad del modelo desde el punto de vista ambiental, económico y de garantía de suministro. El despliegue de medidas de ahorro y optimización energética en el sector de la edificación se considera crucial en la medida que es uno de los principales consumidores de energía del espacio comunitario. Con este fin, los estados miembros se han comprometido a promover la construcción y rehabilitación integral de edificios con una alta calificación energética y de consumo de energía casi nulo para alcanzar las metas impuestas por las instituciones europeas para los años 2020 y 2030. Precisamente, las redes de distrito (district heating and cooling) son un buen ejemplo del uso de tecnologías altamente eficientes para conseguir bajas emisiones de dióxido de carbono y un ahorro energético significativo en edificios 
e instalaciones. Este trabajo analiza un proyecto innovador en este ámbito, el District Heating and Cooling (Xarxa Espavilada) de Olot, que posibilita que un área de 40.000 metros cuadrados funcione exclusivamente con energías renovables mediante una fórmula de trilogía energética (biomasa, geotermia y fotovoltaica).

RESUM: L'eficiència energètica forma part, juntament amb la reducció d'emissions de gasos d'efecte hivernacle i el foment de les energies renovables, dels objectius prioritaris de la política energètica de la UE amb vista a garantir la sostenibilitat del model des del punt de vista ambiental, econòmic i de garantia de subministrament. El desplegament de mesures d'estalvi i optimització energètica en el sector de l'edificació es considera crucial en la mesura que és un dels principals consumidors d'energia de l'espai comunitari. A aquest efecte, els estats membres s'han compromès a promoure la construcció i rehabilitació integral d'edificis amb una alta qualificació energètica i de consum d'energia gairebé nul per aconseguir les metes imposades per les institucions europees per als anys 2020 i 2030. Precisament, les xarxes de districte (district heating and cooling) són un bon exemple de l'ús de tecnologies altament eficients per aconseguir baixes emissions de diòxid de carboni $i$ un estalvi energètic significatiu en edificis i instal-lacions. Aquest treball analitza un projecte innovador en aquest àmbit, el District Heating and Cooling (Xarxa Espavilada) d'Olot, que possibilita que un àrea de 40.000 metres quadrats funcioni exclusivament amb energies renovables mitjançant una formula de trilogia energètica (biomassa, geotèrmia i fotovoltaica).

ABSTRACT: Together with the reduction of greenhouse gas emissions and the promotion of renewable energies, energy efficiency is one of the priority objectives of the EU's energy policy with a view to ensuring the sustainability of the model in terms of environmental and economic sustainability and security of supply. The deployment of energy saving and optimisation measures in the building sector is considered crucial as it is one of the main energy consumers of the Community area. To this end, the member states have committed themselves to promoting the construction and comprehensive refurbishment of buildings with a high energy qualification and nearly zero energy building in order to achieve 
the targets set by the European institutions for the years 2020 and 2030. District heating and cooling networks are a good example of the use of highly efficient technologies to obtain low carbon dioxide emissions and significant energy savings in buildings and installations. This work analyzes an innovative project in this field, the District Heating and Cooling (Xarxa Espavilada) in Olot, which allows an area of 40,000 square meters to operate exclusively with renewable energy through a formula of energy trilogy (biomass, geothermal and photovoltaic).

PALABRAS CLAVE: cambio climático - sostenibilidad urbana - eficiencia energética - edificación - district heating and cooling (DHC).

PARAULES CLAU: canvi climàtic - sostenibilitat urbana - eficiència energètica - edificació - district heating and cooling (DHC).

KEY WORDS: climate change - urban sustainability - energy efficiency building - district heating and cooling (DHC).

SUMARIO: I. El ineludible viraje de las políticas locales hacia objetivos de eficiencia energética. II. Los retos de la eficiencia energética en el sector de la edificación. 1. El contexto europeo: el paquete energético de la UE de 2016 y la Directiva (UE) 2018/844 del Parlamento Europeo y del Consejo de 30 de mayo de 2018. 2. La eficiencia energética de los edificios en el ordenamiento jurídico español. a) Los requisitos básicos de la edificación en materia de habitabilidad: la eficiencia energética de los edificios. b) El certificado de eficiencia energética de los edificios. III. Un caso de estudio: eficiencia energética e integración de recursos energéticos renovables mediante el District Heating and Cooling (xarxa espavilada) de Olot. 1. Reducción del consumo energético y fomento de renovables mediante las redes de calor y frío. 2. El District Heating and Cooling (Xarxa Espavilada de climatización) de Olot. a) Cuestiones previas. b) La prueba piloto: EspaiZero. c) La Xarxa Espavilada como paradigma de alimentación energéticamente eficiente de un entorno urbano. i. Ámbito de aplicación del proyecto y modelo de producción energética. ii. Funcionamiento y optimización del sistema energético combinado. IV. Conclusiones. V. Bibliografía.

\section{EL INELUDIBLE VIRAJE DE LAS POLÍtiCAS LOCALES HACIA OBJETIVOS DE EFICIENCIA ENERGÉTICA ${ }^{1}$}

Si bien el impulso a las políticas verdes a escala nacional y subnacional con el fin de transformar el modelo económico imperante corresponde principalmente

\footnotetext{
1 Este trabajo ha sido realizado en el marco del proyecto de investigación financiado por el Ministerio de Economía y Competitividad "Constitución climática global: gobernanza y Derecho en un contexto complejo" DER2016-80011-P.
} 
a los estados -y a las regiones con capacidad legislativa-, en el marco de los objetivos fijados por las instituciones comunitarias, no hay duda de que las administraciones locales también desempeñan un papel destacado en el reto de avanzar hacia un crecimiento sostenible e inclusivo que promueva un uso eficiente de recursos y combata el cambio climático. En un mundo en el que la mayor parte de la población reside en áreas urbanas, las ciudades están obligadas a aportar soluciones proactivas que contribuyan a rebajar la escala del daño perpetrado al medio ambiente. En consecuencia, la lucha contra el cambio climático y en pos de la sostenibilidad global debe empezar "en casa", en las ciudades, con iniciativas lideradas por las instituciones públicas, pero también con proyectos bottom-up que integren e involucren directamente a la comunidad. Por su proximidad a los actores económicos y sociales y a la ciudadanía y por el conocimiento directo del territorio, las entidades locales están plenamente capacitadas para formular estrategias que ayuden a frenar el acelerado deterioro ambiental; estrategias que, de resultar eficaces, pueden replicarse en otras tantas ciudades. Precisamente, la afectación progresiva de las políticas europeas al ámbito local "ha conducido a darles visibilidad y responsabilidades, aun de forma incipiente, en la ejecución de aquellas políticas" (Galera Rodrigo, 2017: p. 77). Los entes locales tienen un papel destacado en el desarrollo de las Agendas 21 y en la formulación e implementación de políticas de sostenibilidad urbana, lo que las convierte en agentes experimentados en la búsqueda de nuevas estrategias para mitigar el cambio climático en sus distintos frentes, y uno de ellos es el de la mejora de la eficiencia energética de su parque edificado. La optimización del rendimiento energético en el sector de la construcción se vislumbra como parte destacada del proceso de reducción del uso de combustibles fósiles, en aras a disponer de un sistema energético sostenible, competitivo, seguro y descarbonizado. La eficiencia energética se define como "la relación entre la producción de un rendimiento, servicio, bien o energía, y el gasto de energía" (art. 2.4 de la Directiva 2012/27/UE, de 25 de octubre de 2012, relativa a la eficiencia energética, por la que se modifican las Directivas 2009/125/CE y 2010/30/UE, y por la que se derogan las Directivas 2004/8/CE y 2006/32/CE). Para conseguir esa eficiencia energética, es fundamental disponer de un marco regulatorio y de una planificación que favorezcan los procesos de transición hacia una economía hipocarbónica, en especial, en lo que atañe a los 
usos del suelo y la edificación, apostando por un modelo arquitectónico compacto que reduzca el uso del automóvil y mejore el diseño de las viviendas y otras construcciones e instalaciones con criterios más estrictos de sostenibilidad con el fin de reducir la demanda energética asociada al uso típico de los edificios. En este sentido, este trabajo dedica unas páginas a exponer una iniciativa pionera de eficiencia energética, la primera red de climatización de Cataluña que funciona a partir de un sistema híbrido de energías renovables (geotermia, fotovoltaica y biomasa). Esta iniciativa se inscribe en el marco del ambicioso paquete integrado de medidas sobre cambio climático y energía de la UE "Triple 20" proyectado por las instituciones comunitarias para favorecer una economía que genere bajas emisiones de carbono y consuma menos energía. ${ }^{2}$ Los entes locales se han adherido a esta estrategia a través del Pacto de los Alcaldes y de la elaboración de los correspondientes Planes de Acción de Energía Sostenible (PAES) y Planes de Acción para el Clima y la Energía Sostenible (PACES) presentados en aplicación, respectivamente, del Pacto para 2020 y del Pacto para 2030.

\section{LOS RETOS DE LA EFICIENCIA ENERGÉTICA EN EL SECTOR DE LA EDIFICACIÓN}

\section{El contexto europeo: el paquete energético de la UE de 2016 y la Directiva} (UE) 2018/844 del Parlamento Europeo y del Consejo de 30 de mayo de 2018

El Protocolo de Kioto de la Convención Marco sobre Cambio Climático de las Naciones Unidas acordado en 1997 señala el arranque de las políticas comunitarias en pos de una transición energética de largo recorrido que debe conducirnos, en 2050, a un modelo eficiente y prácticamente libre de energías

\footnotetext{
${ }^{2}$ Con el fin de hacer efectivo este programa, la UE permite la compra de derechos de emisión, de conformidad con el principio de límites máximos y comercio de derechos (Directiva 2003/87/CE de 13 de octubre de 2003, por la que se establece un régimen para el comercio de derechos de emisión de gases de efecto invernadero en la Comunidad y por la que se modifica la Directiva 96/61/CE). Este régimen se aplica en los 28 países de la UE además de Islandia, Liechtenstein y Noruega. Dentro del límite sobre la cantidad total de determinados gases de efecto invernadero que pueden emitir las instalaciones incluidas en el régimen, las empresas pueden comprar o vender derechos de emisión, así como cantidades limitadas de créditos internacionales de proyectos de reducción de emisiones en todo el mundo.
} 
fósiles. El fomento de las energías renovables ${ }^{3}$ y de la eficiencia energética en sus distintos frentes (edificación, industria, transportes, procesos de producción y manufacturación, servicios energéticos...), que confluyen en el objetivo finalista de reducir progresivamente las emisiones de gases de efecto invernadero, constituyen los pilares de la planificación estratégica de la UE en materia de integración energética y medioambiental, cuya concreción normativa y ejecución material se deriva a los estados miembros. Las instituciones comunitarias han ido aumentando gradualmente las exigencias de ahorro en el consumo de energía, exigencias que, en el proceso de transposición nacional, han dado lugar a una elevada producción normativa interna (estatal, autonómica e, incluso, local), aunque destaca, por negativo, el hecho de que España no disponga aún de una ley de eficiencia energética y energías renovables, tal y como exigía la Ley 2/2011, de 4 de marzo, de Economía Sostenible (DF 22ª̣). ${ }^{4}$

La reducción del consumo energético, el fomento de las renovables (eólica, hidráulica, solar, fotovoltaica...) y la eficiencia energética son objetivos que se encuentran en el centro de la diana de una serie de documentos e iniciativas jurídicas y financieras articuladas por la UE para incentivar el uso de tecnologías ecológicas. Entre ellos, pueden citarse los libros verdes "Sobre la eficiencia energética: cómo hacer más con menos" (2005) y "Estrategia europea para una energía sostenible, competitiva y segura" (2006), el Plan de Eficiencia Energética 2011 y las comunicaciones de la Comisión "Una política energética para Europa" (2007), “Energía 2020" (2010), "Hoja de ruta hacia una Europa eficiente en el uso de los recursos" (2011) y "Hoja de ruta hacia una economía hipocarbónica competitiva en 2050" (2011) -en la que se señala, desde esta perspectiva, la

\footnotetext{
3 Vid. la Directiva 2009/28/CE de 23 de abril, relativa al fomento del uso de la energía procedente de fuentes de energías renovables. Esta Directiva se centra en el fomento y apoyo a las energías limpias con el objetivo de que los países de la UE consigan una autonomía energética que no les haga depender del abastecimiento exterior. Contiene, asimismo, previsiones sobre el fomento de las energías renovables en la edificación.

${ }^{4}$ Comunidades autónomas como Castilla-La Mancha y Andalucía ya disponen de normativa específica en la materia, en tanto que, a nivel estatal, existe una regulación dispersa (RD 110/2015, de 20 de febrero, sobre residuos de aparatos eléctricos y electrónicos; RD 413/2014, de 6 de junio, por el que se regula la actividad de producción de energía eléctrica a partir de fuentes de energía renovables, cogeneración y residuos; Ley 24/2013, de 26 de diciembre, del Sector Eléctrico; RD-ley 1/2012, de 27 de enero, por el que se procede a la suspensión de los procedimientos de preasignación de retribución y a la supresión de los incentivos económicos para nuevas instalaciones de producción de energía eléctrica a partir de cogeneración, fuentes de energía renovables y residuos; etc.). En la actualidad, se encuentra en elaboración un anteproyecto de Ley estatal de Cambio Climático y Transición Energética.
} 
necesidad de centrarse más en la eficiencia energética-, así como otros instrumentos más específicos en materia de fomento de inversiones como el Fondo Mundial para la Eficiencia Energética y las Energías Renovables, la iniciativa comunitaria del Banco Europeo de Inversiones "Iniciativa de financiación de la energía sostenible", el Fondo Europeo para la Energía, el Cambio Climático y la Infraestructura, además de las medidas contenidas en el Reglamento (CE) núm. 1080/2006 de 5 de julio de 2006, relativo al Fondo Europeo de Desarrollo Regional y el Programa Marco para la Innovación y la Competitividad. ${ }^{5}$ En paralelo a estas iniciativas de soft law, se ha ido configurando un marco regulatorio comunitario sobre eficiencia energética para disminuir la dependencia energética del exterior, mejorar la competitividad de las empresas y reducir las emisiones de gases de efecto invernadero. La normativa dictada en este ámbito engloba cuestiones como el ecodiseño de productos relacionados con la energía (Directiva 2009/125/CE), el etiquetado energético [Reglamento (UE) 2017/1369 de 4 de julio de 2017] y el uso final de la energía y los servicios energéticos (Directiva 2006/32/CE), si bien es en la Directiva 2012/27/UE donde se establecen disposiciones generales sobre eficiencia energética que cubren desde la producción y distribución de la energía hasta su consumo final. ${ }^{6}$ La eficiencia energética de los edificios se regula por vez primera en la Directiva 2002/91/CE de 16 de diciembre de $2002,{ }^{7}$ sustituida

\footnotetext{
5 Vid. Buñuel, "Los instrumentos económicos como incentivo a la eficiencia energética", p. 369384.

${ }^{6}$ El referente normativo en materia de eficiencia energética lo constituye la Directiva 2012/27/UE de 25 de octubre de 2012, por la que se modifican las Directivas 2009/125/CE y 2010/30/UE, y por la que se derogan las Directivas 2004/8/CE y 2006/32/CE. Esta Directiva crea un marco común para fomentar la eficiencia energética dentro del territorio comunitario y establece acciones concretas a fin de alcanzar un importante ahorro de energía acumulado en el periodo 2014-2020 -entre las que también se incluyen referencias a la edificación, como el incentivo a las empresas de servicios energéticos que realizan inversiones en los edificios para optimizar su consumo energético-. Muy específicamente, el art. 7 establece la obligación de que cada Estado miembro justifique una cantidad de ahorro de energía acumulado para ese periodo. Para hacer efectivo el cumplimiento de esas obligaciones anuales de ahorro energético, los estados deben realizar una contribución financiera anual al Fondo Nacional de Eficiencia Energética, por el importe resultante de multiplicar su obligación de ahorro anual por la equivalencia financiera correspondiente (Vid. la Orden ETU/257/2018, de 16 de marzo, por la que se establecen las obligaciones de aportación al Fondo Nacional de Eficiencia Energética en el año 2018). Para una visión general sobre el papel que la eficiencia energética tiene en la reducción de emisiones de gases contaminantes y en la lucha contra el cambio climático y las medidas de ahorro establecidas en distintos sectores de actividad, vid. González Ríos y Ávila Rodríguez (coords.), Estudios sobre la normativa reguladora de la eficiencia energética. Especial referencia a su incidencia en las Administraciones públicas, Cizur Menor: Thomson Reuters-Aranzadi, 2016.

7 La Directiva 2002/91/CE estableció unos requisitos mínimos de eficiencia energética para los edificios nuevos y los reformados cuando su superficie útil total fuera superior a 1.000 metros
} 
posteriormente por la Directiva 2010/31/UE de 19 de mayo de 2010, relativa a la eficiencia energética de los edificios. Sus disposiciones amplían los requisitos mínimos de eficiencia energética que deben cumplir los edificios de nueva planta y los que son objeto de reforma, modifica la metodología de cálculo de la eficiencia energética (introduce el concepto de "niveles óptimos de rentabilidad") y establece el procedimiento para su certificación energética y para la realización de las inspecciones periódicas de eficiencia energética. Pero sin duda la novedad más destacable es la inclusión del concepto de "edificio de consumo de energía casi nulo" (nearly Zero Energy Building).

Casi el $50 \%$ del consumo de energía final de la UE se concentra en funciones de calefacción y refrigeración y de ella el 80 \% se consume en edificios, datos que ponen de manifiesto el potencial de la rehabilitación energética de edificios como herramienta imprescindible para incrementar el ahorro energético. Entre los sectores implicados en el objetivo de avanzar en la eficiencia se encuentra especialmente el de la construcción que, si bien tras el estallido de la burbuja inmobiliaria se sumió en un estado de sopor, ha visto en el proceso de mutación de las energías carbónicas a las energías limpias un revulsivo para su reactivación económica. Así lo disponen la Directiva 2009/28/CE, para la cual la construcción constituye un sector estratégico, y la Directiva 2012/27/UE, al establecer que el sector de la edificación y los equipamientos constituye uno de los ámbitos más bien posicionados para contribuir al ahorro y la eficiencia energética. La Comisión Europea lo ha puesto de relieve en sus Comunicaciones "La eficiencia energética y su contribución a la seguridad de la energía y al marco 2030 para las políticas en materia de clima y energía" y "Estrategia Marco para una unión de la energía resiliente con una política climática prospectiva junto con la movilidad, los servicios públicos, la pesca y la agricultura" (Paquete "Unión de la Energía"). Asimismo, en su Informe 2/2016 "El papel del sector de la construcción en el crecimiento económico: competitividad, cohesión y calidad de vida", el Consejo Económico y Social ha hecho hincapié en las oportunidades que se abren para este sector en el ámbito de las energías renovables y la

cuadrados e introdujo el certificado de eficiencia energética. La Directiva 2010/31/UE se complementa con el Reglamento Delegado (UE) núm. 244/2012, de la Comisión, de 16 de enero de 2012, que configura un marco metodológico comparativo para calcular los niveles óptimos de rentabilidad de los requisitos mínimos de eficiencia energética de los edificios y de sus elementos. 
inversión en mejora de la eficiencia energética, ${ }^{8}$ así como en el desarrollo de infraestructuras energéticas de interconexión (de electricidad, gasistas y de dióxido de carbono). La descarbonización de la economía se presenta, a la vez, como un reto medioambiental y como una oportunidad para reorientar el crecimiento económico y crear empleo. ${ }^{9}$

Las instituciones comunitarias han establecido un marco común de medidas para el fomento de la eficiencia energética en su territorio que imponen una serie de tareas a los estados miembros encaminadas a descarbonizar el suministro de energía y reducir el consumo energético final de sus parques inmobiliarios. Estas obligaciones traen causa del despliegue de una serie de paquetes legislativos en materia de desarrollo de energías renovables y de eficiencia energética aprobados en 2007, 2014 y 2016 para el cumplimiento de objetivos nacionales a corto, medio y largo plazo (2020, 2030 y 2050). El primer paquete de medidas tiene su origen en la Comunicación de la Comisión "Una política energética para Europa" (enero de 2007), que establecía las líneas maestras de la política energética comunitaria e incluía un Plan de Acción con medidas y objetivos concretos (objetivos 20-20-20) para hacer frente al cambio climático. En el escenario instaurado por esta Comunicación y por las directivas 2009/28/CE, relativa al fomento del uso de la energía procedente de fuentes de energías renovables, 2010/31/UE, sobre eficiencia energética de los edificios, y 2012/27/UE, relativa a la eficiencia energética, los estados son responsables de garantizar la consecución de los objetivos establecidos para 2020, a saber, que se reduzcan las emisiones de gases de efecto invernadero en un $20 \%$, respecto a 1990, que el consumo energético total de la UE proceda en un mínimo del $20 \%$ de fuentes renovables ( $10 \%$ de origen renovable en transporte) y que se consiga alcanzar un ahorro energético en el mismo porcentaje del 20\% respecto a 1990. En España, estos objetivos de sostenibilidad se plasmaron en la Ley 2/2011, de 4 de marzo, de Economía Sostenible (art. 78 "Objetivos nacionales en materia

\footnotetext{
${ }^{8}$ El informe apunta que las energías renovables son imprescindibles en un esquema de generación de largo plazo y que existe un amplio margen para promover la construcción de plantas que dispongan de este tipo de fuentes energéticas. También destaca que el sector de la construcción está altamente involucrado en la eficiencia energética, y añade que un 30\% del consumo final energético de 2013 se imputa al sector de la edificación (frente a un 37\% del sector transporte y un $33 \%$ de la industria), del cual un $60 \%$ corresponde a la edificación residencial, un $28 \%$ a la edificación no residencial privada y un $12 \%$ a la no residencial pública (p. 69-70).

9 Vid. el informe de la OCDE, Employment Implications of Green Growth: Linking jobs, growth, and green policies, 2017.
} 
de ahorro y eficiencia energética y energías renovables") que asumía ese mínimo de participación de las energías renovables en el consumo energético y de reducción de la demanda de energía primaria. ${ }^{10}$ En octubre de 2014, el Consejo Europeo aprobó unos nuevos objetivos en el marco de actuación de la UE en materia de energía y clima hasta el año 2030, en línea con la Comunicación "Un marco estratégico en materia de clima y energía para el período 2020-2030" (enero de 2014). A su tenor, los estados se comprometen a una rebaja de las emisiones de gases de efecto invernadero de un mínimo del $40 \%$ en comparación con los niveles del $1990^{11}$ y a incrementar la cuota mínima de energías renovables, que se fija en un $27 \%$ del consumo energético de la UE (compromisos vinculantes), así como a conseguir un ahorro mínimo del $27 \%$ en materia de eficiencia energética respecto de los valores de 1990 (objetivo revisable antes de 2020). ${ }^{12}$ También el Acuerdo de París de noviembre de 2015 sobre cambio climático (21 Conferencia de las Partes en la Convención Marco de las Naciones Unidas sobre el Cambio Climático, COP21) ${ }^{13}$ considera, en apoyo de las políticas comunitarias, la descarbonización del parque inmobiliario y su eficiencia energética como una de las medidas necesarias para minorar los

\footnotetext{
10 Con esta finalidad, se prescribió la formulación de planes nacionales de ahorro y eficiencia energética y planes de energías renovables, que contemplaran medidas de orientación y fomento de la oferta y el consumo energético para cumplir con los objetivos de la UE y que permitieran la posibilidad efectiva de desarrollo de las energías renovables en todas las comunidades autónomas (art. 78.4 Ley 2/2011).

${ }^{11}$ En los sectores sujetos y no sujetos al régimen de comercio de derechos de emisión, la reducción debe ser, respectivamente, del 43\% y 30\%, respecto de los valores de 2005.

${ }^{12} \mathrm{El}$ art. 7 de la Directiva de eficiencia energética fija los parámetros de ahorro de energía para los estados miembros. En noviembre de 2016, la Comisión Europea propuso un objetivo de eficiencia energética vinculante del $30 \%$ para 2030, que fue aprobado por el Consejo, frente al $35 \%$ acordado por el Parlamento. Finalmente, las instituciones europeas llegaron a un acuerdo no vinculante por el cual el objetivo de ahorro de energía para 2030 se fija en el 32,5\% (con un porcentaje del $0,8 \%$ anual) y se introduce una cláusula de revisión al alza para 2023 . Este acuerdo debe ser refrendado por el Parlamento y los ministros de los estados miembros.

${ }^{13}$ El Acuerdo de París toma el relevo del Protocolo de Kioto (que extingue su eficacia en 2020) en materia de reducción de emisiones de gases de efecto invernadero. Este acuerdo global y vinculante propone un plan de actuación para estabilizar el calentamiento del planeta muy por debajo de los 2 grados centígrados con respecto a los niveles preindustriales e impulsar esfuerzos para limitar el aumento de la temperatura por debajo de 1,5 grados centígrados. Con este fin, los gobiernos nacionales se obligan a formular planes generales de actuación contra el cambio climático, informando de sus logros cada 5 años para establecer objetivos más ambiciosos. La COP22, celebrada en Marrakech en noviembre de 2016, ha fijado un calendario de trabajo para elaborar los criterios de seguimiento y desarrollo del Acuerdo. Vid. asimismo el Reglamento (UE) 2018/842, de 30 de mayo de 2018, sobre reducciones anuales vinculantes de las emisiones de gases de efecto invernadero por parte de los Estados miembros entre $2021 \mathrm{y}$ 2030 que contribuyan a la acción por el clima, con objeto de cumplir los compromisos contraídos en el marco del Acuerdo de París, y por el que se modifica el Reglamento (UE) núm. 525/2013.
} 
niveles de emisiones de gases de efecto invernadero (que la UE propone reducir para 2050 en un $80-95 \%$ respecto de los niveles existentes en 1990). ${ }^{14}$

El último paquete de medidas presentado por la UE es el denominado Paquete de Invierno: "Energía limpia para todos los europeos" (noviembre de 2016), ${ }^{15}$ compuesto por ocho propuestas normativas que consolidan el liderazgo europeo en la transición hacia energías limpias y buscan preservar su competitividad en el sector energético. Este paquete pone sobre la mesa la necesidad de abordar retos climáticos más exigentes, de acuerdo con la Hoja de ruta para 2050, priorizando la eficiencia energética, facilitando la penetración en el mercado de las energías renovables y estableciendo la obligación de elaborar Planes Nacionales Integrados de Energía y Clima que contengan los objetivos, hitos y contribuciones nacionales para cada una de las cinco dimensiones de la Unión de la Energía (una de las cuales es la eficiencia energética), además de una descripción de las políticas y medidas previstas para su cumplimiento. ${ }^{16}$ Precisamente, la necesidad de seguir avanzando en la consecución de un modelo energético seguro, competitivo y ambientalmente sostenible y, más específicamente, de perseverar en la descarbonización del parque inmobiliario europeo, ha llevado a la revisión y modificación de las directivas 2010/31/UE, sobre eficiencia energética de los edificios, y 2012/27/UE, relativa a la eficiencia energética, mediante la Directiva (UE) 2018/844 de 30 de mayo de 2018 (en vigor desde el 9 de julio). ${ }^{17}$ Esta Directiva forma parte del conjunto de medidas sobre energía limpia presentado por la Comisión en noviembre de 2016, uno de cuyos propósitos es la reevaluación del objetivo de eficiencia energética de la

\footnotetext{
14 La Hoja de Ruta hacia una economía hipocarbónica competitiva en 2050 (2013) dispone que ese año la UE deberá haber reducido sus emisiones un $80 \%$ por debajo de los niveles de 1990 (en el ínterin se establecen reducciones progresivas del $40 \%$ en 2030 y del $60 \%$ en 2040 ) y plantea que la transición hacia una economía de baja emisión de carbono por parte de los sectores que realizan mayores emisiones, como la construcción, puede hacerse de forma rentable.

${ }^{15}$ Comunicación de la Comisión Europea, Energía limpia para todos los europeos, Bruselas, 30.11.2016 $\operatorname{COM}(2016) 860$ final.

16 Este paquete contiene propuestas de revisión de las principales directivas energéticas: eficiencia energética (Directiva 2012/27/UE), eficiencia energética en edificios (Directiva 2010/31/UE) y fomento del uso de energía procedente de fuentes renovables (Directiva 2009/28/CE).

17 El plazo máximo de que disponen los estados miembros para realizar la transposición de la Directiva 2018/844 a sus ordenamientos jurídicos internos es el 10 de marzo de 2020 (art. 3). También se establece que la Comisión deberá revisar la aplicación de la Directiva 2010/31/UE, a más tardar el 1 de enero de 2026, teniendo en cuenta la experiencia adquirida y los progresos realizados durante su aplicación (art. 19 de la Directiva 2010/31/UE en la redacción dada por la Directiva 2018/844).
} 
UE para 2030. Con este fin, la Directiva intenta allanar el camino a las inversiones en este ámbito ayudándose del refuerzo financiero que supone la inclusión de los Fondos Estructurales y de Inversión Europeos y los Fondos Europeos para Inversiones Estratégicas. Destaca en la Directiva la priorización por la eficiencia energética frente a las energías renovables («primero, la eficiencia energética», Considerando 7ํㅜ). Esta opción tiene su lógica si consideramos que la reducción de las necesidades energéticas $-\mathrm{y}$ el consiguiente ahorro en las emisiones de gases de efecto invernadero- es un objetivo más a corto plazo, más fácil de materializar que el despliegue de tecnología para impulsar fuentes primarias de origen renovable. Una vez reducido el consumo energético mediante soluciones eficientes en materia de suministro, conversión y utilización de la energía que incorporen la implementación de un sistema de gestión y monitorización, el siguiente nivel prestacional debe conseguirse recurriendo a las energías renovables.

Como novedades más significativas de la Directiva 2018/844 figuran el establecimiento de una estrategia de renovación del parque de edificios a largo plazo encaminada a su descarbonización antes de 2050 así como la determinación de fórmulas de financiación más adecuadas a tal efecto, sobre la base de vincular los incentivos financieros para la mejora de la eficiencia energética en la reforma de edificios al ahorro de energía previsto o logrado en atención a determinados criterios (la eficiencia energética de los equipos 0 materiales utilizados para la reforma, los valores estándar para el cálculo del ahorro de energía en los edificios, la mejora lograda tras la reforma mediante la comparación de los certificados de eficiencia energética expedidos antes y después de la reforma, los resultados de una auditoría energética y los resultados proporcionados por otros métodos). Asimismo, se introduce un indicador de preparación para aplicaciones inteligentes de los edificios que evalúa su capacidad para ajustarse a las necesidades del usuario y proporcionar información sobre consumo energético operacional. También se simplifican las inspecciones de las instalaciones de calefacción y aire acondicionado mediante la introducción de sistemas de control y automatización de los edificios, ${ }^{18}$ se

${ }^{18}$ El Considerando $37^{\circ}$ de la Directiva 2018/844 señala que la automatización de los edificios y el seguimiento electrónico de sus instalaciones técnicas son una alternativa eficaz a las inspecciones físicas, especialmente en el caso de grandes instalaciones, y puede proporcionar 
establecen inspecciones periódicas de las partes accesibles de los sistemas e instalaciones de calefacción y de aire acondicionado o de las instalaciones combinadas (calefacción / ventilación y aire acondicionado / ventilación) con una potencia nominal útil superior a $70 \mathrm{~kW}^{19} \mathrm{y}$, por último, se fomenta la electromovilidad mediante la introducción de requisitos específicos para apoyar la implantación de infraestructuras de recarga en los aparcamientos de edificios residenciales y no residenciales. En particular, la Directiva se propone avanzar en la mejora de la eficiencia energética de los edificios acelerando su renovación rentable y, con este objetivo, introduce una disposición (art. 2 bis) en la Directiva 2010/31/UE, según la cual los estados miembros deben establecer estrategias a largo plazo para respaldar y estimular la renovación de su parque inmobiliario, residencial y no residencial, público y privado, con el fin de descarbonizarlo y transformarlo en altamente eficiente energéticamente antes de 2050, mediante su conversión en edificios de consumo de energía casi nulo. Cada estrategia nacional debe contener: a) una visión general de su parque inmobiliario, con la previsión del porcentaje de edificios renovados para 2020, b) la determinación de enfoques económicamente rentables de las reformas según el tipo de edificio y la zona climática, teniendo en cuenta, cuando proceda, los posibles puntos de activación correspondientes en el ciclo de vida del edificio; c) políticas y acciones que estimulen renovaciones profundas y económicamente rentables de los edificios, entre ellas las renovaciones profundas por fases, y el apoyo de medidas y reformas económicamente rentables específicas, por ejemplo mediante la introducción de un sistema voluntario de pasaportes de renovación de edificios; d) una visión general de las políticas y acciones dirigidas a los segmentos de edificios menos eficientes del parque inmobiliario nacional, los dilemas causados por la contraposición de incentivos, los fallos de mercado y un esbozo de las acciones nacionales pertinentes que contribuyan a paliar el problema de la pobreza energética; e) políticas y acciones destinadas a todos

un ahorro energético considerable y económicamente rentable tanto a los consumidores como a las empresas. Más concretamente, la instalación de tales equipos es la alternativa más rentable económicamente en grandes edificios no residenciales y de apartamentos de una dimensión suficiente como para recuperar la inversión en menos de tres años.

${ }^{19} \mathrm{La}$ inspección incluirá una evaluación del rendimiento y del dimensionado del generador de calor en comparación con los requisitos de calefacción del edificio, así como del rendimiento de las instalaciones del aire acondicionado y de su dimensionado en comparación con los requisitos de refrigeración del edificio. 
los edificios públicos; f) un resumen de las iniciativas nacionales para promover las tecnologías inteligentes y edificios y comunidades bien conectados, así como la capacitación y la enseñanza en los sectores de la construcción y de la eficiencia energética, y g) un cálculo del ahorro de energía y de los beneficios de mayor alcance, como los relacionados con la salud, la seguridad y la calidad del aire, que se esperan obtener. Asimismo, los estados deben establecer una hoja de ruta con medidas e indicadores de progreso mensurables establecidos nacionalmente con relación al objetivo a largo plazo de 2050, además de objetivos indicativos para 2030, 2040 y 2050.

Entre las medidas concretas de mejora de la eficiencia que contribuyen a reducir la demanda de energía, la Directiva 2018/844 señala la necesidad de garantizar el aislamiento completo y homogéneo del edificio, incluyendo balcones, ventanas, tejados, paredes, puertas y suelos, así como de prevenir que la temperatura de cualquier superficie interna del edificio quede por debajo de la temperatura del punto de rocío. No obstante, estas medidas no deben centrarse únicamente en la envolvente del edificio, sino que deben incluir todos los elementos pertinentes y los sistemas técnicos del mismo. La Directiva también valora la integración de soluciones de tipo natural, como una vegetación urbana bien diseñada, tejados verdes y muros que aporten aislamiento y sombra a los edificios, por su capacidad de reducir la necesidad de calefacción y refrigeración y de mejora de la eficiencia energética de los edificios. Finalmente, siempre que sea técnica, medioambiental y económicamente viable, tanto los edificios de nueva construcción como los sujetos a reformas importantes deben contar con instalaciones alternativas de alta eficiencia que proporcionen unas condiciones climáticas interiores saludables (arts. 6 y 7 de la Directiva 2010/31/UE en la redacción dada por la Directiva 2018/844). Condicionado también a su viabilidad, los edificios nuevos deberán estar equipados con dispositivos de autorregulación que regulen separadamente la temperatura ambiente en cada espacio interior 0 , en casos justificados, en una zona de calefacción seleccionada del conjunto del edificio; mientras que, en los edificios existentes, la instalación de este tipo de dispositivos se exigirá, caso de ser viable, cuando se sustituyan los generadores de calor (art. 8 de la Directiva 2010/31/UE en la redacción dada por la Directiva 2018/844). 


\section{La eficiencia energética de los edificios en el ordenamiento jurídico español}

a) Los requisitos básicos de la edificación en materia de habitabilidad: la eficiencia energética de los edificios

Tras una prolongada parálisis, la actividad constructiva vuelve a mostrar síntomas de aceleración a medio plazo. ${ }^{20} \mathrm{Y}$ en este nuevo escenario, la construcción de edificios sostenibles y eficientes y la rehabilitación energética de los existentes se ha convertido en un nicho de negocio muy seductor para las empresas promotoras y constructoras y para las empresas de servicios energéticos.

En la actualidad, el parque residencial español, con aproximadamente 25 millones de viviendas, representa el $31 \%$ del consumo final y alrededor del $11 \%$ de las emisiones directas de $\mathrm{CO} 2$ de origen energético. De estas viviendas, casi dos tercios fueron construidas antes de 1990 , de modo que más del $85 \%$ del parque actual tiene una deficiente calificación energética, tipo $E$ o inferior. ${ }^{21}$ No es de extrañar que nuestro país -que ostenta el dudoso honor de situarse entre los puestos de cabeza de los países dónde las operaciones de transformación urbanística del territorio han sido más voraces, y que dispone del mayor número de viviendas por habitante de la UE-22 haya dedicado una particular atención normativa a la mejora de la eficiencia energética del sector de la edificación, teniendo en cuenta, como ya se ha dicho, que casi la mitad del consumo total de energía del territorio comunitario corresponde al parque inmobiliario. ${ }^{23} \mathrm{La}$ normativa española sobre eficiencia energética se caracteriza, doblemente, por

\footnotetext{
20 Tras la crisis inmobiliaria de esta última década, España ha vuelto a recuperar el liderazgo europeo en el sector de la construcción $(2,2 \%)$, por delante de Suecia $(18 \%)$ y Eslovaquia (16,4\%). Datos: EUROSTAD 2017.

21 Comisión de Expertos de Transición Energética, Análisis y propuestas para la descarbonización, 2018, p. 35.

${ }^{22}$ España dispone de 600 viviendas por cada 1000 habitantes frente a las 450 viviendas de media del resto de países de la UE (González Bustos, 2017a: p. 250).

${ }^{23}$ Así lo destaca la Directiva 2010/31/UE, cuando afirma que: "El 40\% del consumo total de energía en la Unión corresponde a los edificios. El sector se encuentra en fase de expansión, lo que hará aumentar el consumo de energía. Por ello, la reducción del consumo de energía y el uso de energía procedente de fuentes renovables en el sector de la edificación constituyen una parte importante de las medidas necesarias para reducir la dependencia energética de la Unión y las emisiones de gases de efecto invernadero" (Considerando $3^{\circ}$ ).
} 
su profusión y dispersión. ${ }^{24}$ De una parte, porque este objetivo es extrapolable a distintos sectores de actividad que requieren de un marco normativo específico $y$, de otra, por la pluralidad de actores que disponen de un título habilitante para regular la materia, a saber, la UE, el Estado (normativa básica), las comunidades autónomas (normativa de desarrollo y ejecución) y los entes locales (González Ríos, 2017: p. 173). Precisamente, son estos últimos los que mayor protagonismo tienen en la formulación e implementación de planes y actuaciones para garantizar la eficiencia energética en la edificación, merced a sus competencias en materia de urbanismo y protección del medio ambiente urbano (art. 25.2 de la Ley 7/1985, de 2 de abril, reguladora de las Bases del Régimen Local). El compromiso de las ciudades es fundamental en el logro del objetivo de la eficiencia energética y muchas de ellas ya están promoviendo iniciativas para avanzar en la transición energética, de forma independiente o en el marco de distintas redes de intercambio de gobiernos locales para el desarrollo sostenible (ICLEI Local Governments for Sustainability, C40 Cities, etc). Para Los fomentar el uso racional de la energía en cualquiera de sus formas, los municipios pueden desplegar medidas regulatorias como la elaboración de ordenanzas municipales de ecoeficiencia energética y utilización de energías renovables en los edificios y sus instalaciones para regular la edificación con criterios bioclimáticos (alturas máximas, emplazamiento...). ${ }^{25}$ Otras medidas adecuadas pueden ser el reforzamiento de la contratación pública verde -por ejemplo, impulsando la penetración de tecnologías renovables mediante

24 Sobre las medidas implementadas en España y sus resultados hasta la fecha puede consultarse el Informe sobre el Objetivo Nacional de Eficiencia Energética 2020-España, elaborado por la Secretaría de Estado de Energía, Ministerio de Industria, Energía y Turismo (17 de mayo de 2013). Asimismo, téngase en cuenta el Plan para el desarrollo de Tecnologías Estratégicas en el campo de la Energía mediante el cual se promueve la cooperación de la industria para impulsar la transición energética a través de European Industrial Initiatives en diversos ámbitos de las energías renovables (eólica, solar...).

${ }^{25}$ El servicio de alumbrado público es la única materia cuya competencia se reconoce expresamente a los municipios en temas energéticos (art. 26.1.a de la Ley 7/1985). Aunque en un principio los tribunales negaron que los municipios pudieran aprobar ordenanzas en materia de eficiencia energética y energías renovables, la jurisprudencia más reciente del Tribunal Supremo les reconoce esta posibilidad, encuadrándola en las competencias de protección del medio ambiente y de ordenación urbanística, así como en la realización de actividades complementarias de las propias de otras administraciones (esta última competencia ha sido eliminada por la Ley $27 / 2013$, de 27 de diciembre, de Racionalización y Sostenibilidad de la Administración Local). El Tribunal Supremo se vale, para llegar a esta conclusión, del criterio de la "vinculación negativa", por el cual la competencia normativa de las entidades locales no precisa de una específica habilitación legal en cada ámbito sectorial en el que se dicta la ordenanza, siempre que no esté excluida dicha competencia y que no contravenga la correspondiente legislación que resulte de aplicación (Casado Casado y Fuentes i Gasó, 2016: p. 841-842). 
contratos de rendimiento energético en edificios públicos- $-{ }^{26}$ la electrificación del transporte público, la sustitución del alumbrado público por luces LED, la optimización de las instalaciones de potabilización, abastecimiento y depuración de aguas residuales, la aplicación de bonificaciones a los inmuebles que utilicen energías renovables o a las plantas productoras, la organización de campañas informativas para concienciar a la sociedad sobre la implantación de equipos y instalaciones eficientes energéticamente, etc. Es a través del cambio de planteamientos en el urbanismo y la edificación ${ }^{27}$ donde se pueden lograr mayores avances (proyectos de "superislas", urbanismo de tres niveles, introducción de criterios energéticos en el planeamiento -posibilitando que la distancia entre la fuente de generación energética y la fuente de consumo sea lo más pequeña posible, estableciendo criterios de diseño y ordenación urbana que favorezcan la implantación de recursos energéticos renovables como paneles solares fotovoltaicos en cubiertas, barandas y fachadas, sistemas geotérmicos, aerogeneradores mini-eólicos, etc.-).

Las obligaciones establecidas en las Directivas 2002/91/CE y 2010/31/UE han pasado a formar parte del ordenamiento jurídico de manera un tanto fragmentada, a través de normativa sectorial. Debe anotarse que la transposición no se ha producido con carácter integral y ello ha sido denunciado por las instancias europeas (sentencia del Tribunal de Justicia de la UE de 16 de enero de 2014), y lo mismo ocurre con algunas de las exigencias relativas a la eficiencia energética de las edificaciones recogidas en la Directiva 2012/27/UE, ${ }^{28}$ a pesar de haberse superado de largo el plazo de transposición.

España ya había exteriorizado su compromiso con la consecución de mejoras energéticas con anterioridad a la Directiva 2002/91/UE, al exigir que las edificaciones satisficieran, entre otros requisitos, el del ahorro energético. Así lo estipula la Ley 38/1999, de 5 de noviembre, de Ordenación de la Edificación

\footnotetext{
26 Vid. al respecto García Rubio, 2013, p. 93 y ss.

${ }^{27}$ Cuestión aparte son los edificios protegidos por razón de su interés histórico y arquitectónico, que están excluidos de la aplicación de los requisitos de eficiencia energética cuando pudieran causar "alteraciones inaceptables del carácter histórico o de su apariencia" (Directiva 2010/31/UE). Sobre la viabilidad de la restauración de edificios históricos con estándares de alta eficiencia energética, vid. Lucchi, 2015, p. 230-242.

28 Vid. el RD 56/2016, de 12 de febrero, por el que se transpone la Directiva 2012/27/UE de 25 de octubre de 2012, relativa a la eficiencia energética, en lo referente a auditorías energéticas, acreditación de proveedores de servicios y auditores energéticos y promoción de la eficiencia del suministro de energía.
} 
(LOE) al establecer los requisitos básicos que deben cumplimentar los edificios (funcionalidad, seguridad y habitabilidad, art. 3). La eficiencia energética no era ajena a nuestro ordenamiento jurídico: la primera normativa técnica de edificación que regula el aislamiento térmico es la Orden Ministerial de 20 de mayo de 1969 sobre Ordenanzas provisionales de viviendas de protección oficial, que dividía el país en dos zonas en función de las isotermas de verano e invierno. Posteriormente, se aprobarían el Decreto 1490/75, de 12 de junio, que contenía una serie de medidas para lograr un ahorro energético mediante una adecuada construcción de los edificios, y el RD 2429/79, de 6 de julio, que aprobaba la Norma Básica de la Edificación NBE-CT-79, sobre Condiciones Térmicas en los edificios, de obligatoria observancia en todos los proyectos de edificaciones públicas o privadas, y que desarrollaba, en relación con el aislamiento térmico, el RD 1650/1977, de 10 de junio, sobre Normativa de la Edificación. La LOE es una norma que se proyecta a lo largo de todo el proceso de edificación (en sus fases de proyección, construcción, mantenimiento y conservación), en relación con: a) obras de nueva planta, a excepción de las construcciones de escasa entidad constructiva y sencillez técnica que no tengan, de forma eventual o permanente, carácter residencial ni público y se desarrollen en una sola planta; b) obras de modificación, reforma, ampliación o rehabilitación de inmuebles cuando se afecte a la configuración arquitectónica del edificio (esto es, las intervenciones integrales o bien las de carácter parcial cuando comporten una variación esencial de la composición exterior, la volumetría o el conjunto de la estructura o tengan por objeto cambiar los usos característicos del edificio); y c) las obras que supongan una intervención integral en edificaciones catalogadas -o que, en su defecto, posean cualquier clase de protección por su valor histórico-artístico o ambiental- así como aquellas otras de carácter parcial que afecten a los elementos o partes objeto de protección. En concreto, la LOE, al referirse a los requisitos básicos de habitabilidad, ${ }^{29}$ hace hincapié en el ahorro

\footnotetext{
29 Los requisitos básicos relativos a la habitabilidad que deben cumplir los edificios son los siguientes: c.1) Higiene, salud y protección del medio ambiente, con el fin de alcanzar condiciones aceptables de salubridad y estanqueidad en el ambiente interior del edificio y evitar que éste deteriore el medio ambiente en su entorno inmediato, garantizando una adecuada gestión de toda clase de residuos; c.2) Protección contra el ruido, procurando que el ruido percibido no ponga en peligro la salud de las personas y les permita realizar sus actividades de forma satisfactoria; c.3) Ahorro de energía y aislamiento térmico, para conseguir un uso racional de la energía necesaria para la adecuada utilización del edificio; y c.4) Otros aspectos
} 
de energía y en el aislamiento térmico como pilares fundamentales de la eficiencia energética, "de tal forma que se consiga un uso racional de la energía necesaria para la adecuada utilización del edificio" (art. 3.1, letra c.3). ${ }^{30}$ Esta previsión se concreta reglamentariamente mediante el Código Técnico de la Edificación, aprobado por RD 314/2006, de 17 de marzo (CTE), y el Reglamento de Instalaciones Térmicas en Edificios, aprobado por RD 1027/2007, de 20 de julio (RITE).

EI CTE se configura como el marco normativo que establece las exigencias básicas de calidad de los edificios y de sus instalaciones, facilitando el cumplimiento de los requisitos básicos establecidos en el art. 3 de la LOE. En concreto, establece las prestaciones de carácter cualitativo que los edificios deben cumplir en relación con los requisitos básicos de seguridad y habitabilidad de la LOE. Su ámbito de aplicación se extiende, de conformidad con dicha norma, a las edificaciones públicas y privadas cuyos proyectos precisen disponer de la correspondiente licencia o autorización, incluyendo las obras de edificación de nueva construcción que tengan entidad constructiva y, tras la aprobación de la Ley 8/2013, de 26 de junio, de Rehabilitación, Regeneración y Renovación Urbanas (L3R), también las intervenciones en los edificios existentes -en este último caso, el cumplimiento de las exigencias del CTE se justificará en el proyecto o en una memoria suscrita por técnico competente, junto a la solicitud de licencia o de autorización administrativa para las obras-. ${ }^{31}$ EI CTE está formado por Documentos Básicos (DB) de carácter técnico entre los que se incluye el Documento Básico DB-HE de Ahorro de Energía que traspone al ordenamiento jurídico español las exigencias de eficiencia energética de los edificios de la Directiva 2010/31/UE y aboga por promover "el uso racional de la

funcionales de los elementos constructivos o de las instalaciones que permitan un uso satisfactorio del edificio.

30 Vid., como norma antecesora del CTE en materia de aislamiento térmico, el ya citado RD 2429/1979, de 6 de julio, por el que se aprueba la Norma Básica de la Edificación NBE CT-79 "Condiciones térmicas de los edificios".

${ }^{31}$ De conformidad con el art. 3 del CTE, introducido por la L3R (DF 11르), las exigencias requeridas se podrán rebajar justificadamente siempre que se asegure el mayor grado posible de adecuación efectiva, cuando su aplicación no sea viable desde el punto de vista urbanístico, técnico o económico o bien cuando sea incompatible con la naturaleza de la intervención o con el grado de protección del edificio. En el caso de intervenciones en edificios existentes, las condiciones preexistentes relacionadas con las exigencias básicas no se podrán reducir cuando sean menos exigentes que las establecidas en los documentos básicos del CTE, salvo que en éstos se establezca un criterio distinto. Las que sean más exigentes, únicamente podrán reducirse hasta los niveles de exigencia que establecen los documentos básicos. 
energía necesaria para la utilización de los edificios, reduciendo a límites sostenibles su consumo y conseguir asimismo que una parte de este consumo proceda de fuentes de energía renovable" (art. 15.1 CTE). El Documento Básico DB-HE, que ha sido objeto de distintas actualizaciones, ${ }^{32}$ especifica y cuantifica las exigencias en materia de eficiencia energética y energías renovables y los trámites procedimentales para acreditar el cumplimiento de tales exigencias básicas, concretados en forma de métodos de verificación o soluciones avaladas por la experiencia práctica. Este Documento Básico de Ahorro de Energía contiene seis exigencias básicas para lograr edificios de bajo consumo energético y con un elevado nivel de eficiencia energética respecto de las edificaciones más antiguas: las cuatro primeras se encuadran en la eficiencia energética y las restantes en la incorporación de energías solar y renovables en los edificios. Dichas exigencias son las siguientes: DB HEO Limitación del consumo energético (limita el consumo de energía primaria no renovable en los edificios nuevos o ampliados con uso residencial privado. En los edificios con otros usos, la limitación se establece en base a la calificación energética mediante el indicador de consumo energético de energía primaria, que debe alcanzar una eficiencia igual o superior a la clase B); DB HE 1 Limitación de demanda energética (referida tanto a la calefacción como a la refrigeración); DB HE 2 Rendimiento de las instalaciones térmicas; DB HE 3 Eficiencia energética de las instalaciones de iluminación; DB HE 4 Contribución solar mínima de agua caliente sanitaria y DB HE 5 Contribución fotovoltaica mínima de energía eléctrica. El art. 15 CTE establece las exigencias básicas relativas al ahorro de energía (HE):

a) En relación con la limitación de demanda energética, los edificios deben disponer de una envolvente que limite de manera adecuada la demanda

\footnotetext{
32 La DF $3^{\text {a }}$ de la LOE habilita para llevar a cabo las modificaciones y revisiones periódicas de los Documentos Básicos del CTE que sean precisas. Vid. al respecto la Orden FOM/1635/2013, de 10 de septiembre, por la que se actualiza el Documento Básico DB-HE Ahorro de Energía del CTE, que transpone parcialmente las directivas 2010/31/UE y 2009/28/CE e incrementa los niveles de exigencia de los requisitos mínimos de eficiencia energética en edificios de nueva planta, ampliación y rehabilitación. Asimismo, en 2015 se aprobó un nuevo procedimiento para la certificación energética de edificios definido en el Documento Reconocido de "Condiciones técnicas de los procedimientos para la evaluación de la eficiencia energética de los edificios", que ha conllevado la modificación del CTE mediante la Orden FOM/588/2017, de 15 de junio, por la que se modifican el Documento Básico DB-HE Ahorro de energía y el Documento Básico DB-HS Salubridad del CTE (Sección HE 1 del Documento Básico DB-HE y algunos apartados de la sección HS 3 del Documento Básico DB-HS de Salubridad).
} 
energética necesaria para alcanzar el bienestar térmico en función del clima de la localidad, del uso del edificio y del régimen de verano y de invierno, así como de sus características de aislamiento e inercia, permeabilidad al aire y exposición a la radiación solar, reduciendo el riesgo de aparición de humedades de condensación superficiales e intersticiales que puedan perjudicar sus características y tratando adecuadamente los puentes térmicos para limitar las pérdidas 0 ganancias de calor y evitar problemas higrotérmicos en los mismos.

b) En relación con el rendimiento de las instalaciones térmicas, los edificios deben contar con instalaciones térmicas apropiadas para proporcionar bienestar térmico a sus ocupantes, de conformidad con el RITE.

c) En relación con la eficiencia energética de las instalaciones de iluminación, los edificios deben tener instalaciones de iluminación adecuadas a las necesidades de sus usuarios y que sean a la vez energéticamente eficaces, disponiendo de un sistema de control que permita ajustar el encendido a la ocupación real de la zona y de un sistema de regulación que optimice el aprovechamiento de la luz natural, en las zonas que reúnan unas determinadas condiciones.

d) En relación con la contribución solar mínima de agua caliente sanitaria, en los edificios con previsión de demanda de agua caliente sanitaria o de climatización de piscina cubierta, una parte de esa demanda energética térmica debe cubrirse con la implantación de sistemas de captación, almacenamiento y utilización de energía solar de baja temperatura adecuada a la radiación solar global de su emplazamiento y a la demanda de agua caliente del edificio o de la piscina.

e) En relación con la contribución fotovoltaica mínima de energía eléctrica, los edificios deben incorporar sistemas de captación y transformación de energía solar en energía eléctrica por procedimientos fotovoltaicos para uso propio o suministro a la red.

Dentro de los requisitos básicos de la edificación relativos a la habitabilidad de la LOE está el ahorro de energía, que se concreta por medio del CTE con la referencia al rendimiento de las instalaciones térmicas. La Directiva 2010/31/UE establece que, a efectos de optimizar el consumo de energía de las instalaciones térmicas de los edificios, los estados miembros deben fijar unos requisitos en 
relación con la eficiencia energética general, la instalación correcta y el dimensionamiento, control y ajuste adecuados de dichas instalaciones presentes en los edificios existentes (art. 8). Estos requisitos se desarrollan en el RITE, que ha sido objeto de una serie de modificaciones y actualizaciones con el fin de adaptarlo a las nuevas necesidades de ahorro y eficiencia energética, ${ }^{33}$ como consecuencia de la incorporación a nuestro ordenamiento jurídico de las obligaciones derivadas de la mencionada Directiva así como de la necesidad de dar cumplimiento al mandato de revisar periódicamente, en intervalos no superiores a cinco años, la exigencia de eficiencia energética. ${ }^{34}$ EI RITE constituye el instrumento normativo básico regulador de las exigencias de eficiencia energética y de seguridad que deben cumplir las instalaciones térmicas en los edificios, entendidas como las instalaciones fijas de climatización (calefacción, refrigeración y ventilación) y de producción de agua caliente sanitaria, destinadas a atender la demanda de bienestar e higiene de las personas (art. 2.1). Su ámbito de aplicación son las instalaciones térmicas en los edificios de nueva construcción y las instalaciones térmicas que se reformen en los edificios existentes, exclusivamente en lo que a la parte reformada se refiere, así como en lo relativo al mantenimiento, uso e inspección de todas las instalaciones térmicas, con las limitaciones que en el mismo se determinan (art. 2.2). El RITE establece las exigencias técnicas que deben cumplir estas instalaciones (bienestar e higiene, eficiencia energética y seguridad). La exigencia técnica de eficiencia energética busca reducir el consumo de energía convencional de las instalaciones térmicas de calefacción, climatización y producción de agua caliente sanitaria y con ello, las emisiones de gases de efecto invernadero y otros contaminantes atmosféricos, mediante la utilización de sistemas eficientes energéticamente y que permitan la recuperación de energía y la utilización de las fuentes renovables y de las energías residuales. El

${ }^{33}$ En cumplimiento de la obligación de actualización quinquenal, en estos momentos está en proceso de audiencia e información pública una revisión del CTE centrada principalmente en la demanda y consumo energéticos de los edificios (Documento Básico DB-HE). La actualización más reciente hasta la fecha se contiene en el RD 238/2013, de 5 de abril, que elevó las exigencias sobre rendimiento energético de los equipos de generación de calor y frío y de los destinados al movimiento y transporte de fluidos. Vid. asimismo el vigente RD 1826/2009, de 27 de noviembre, que modifica el RITE para conseguir un mayor ahorro energético mediante la limitación de las condiciones de temperatura de grandes superficies y edificios públicos.

${ }^{34}$ La necesidad de proceder a una revisión periódica está establecida en la DF $2^{\mathrm{a}}$. Vid. asimismo el art. 31 RITE. 
diseño, ejecución, mantenimiento y utilización de estas instalaciones térmicas deben cumplir con una serie de exigencias que faciliten la desaparición gradual de equipos generados menos eficientes y de combustibles sólidos contaminantes. Según el art. 12 RITE, estos requerimientos persiguen los siguientes objetivos: a) obtener el mayor rendimiento energético de los equipos de generación de calor y frío, así como de los destinados al movimiento y transporte de fluidos; b) mejorar el aislamiento térmico de los equipos y las conducciones de las instalaciones térmicas; c) dotar a las instalaciones de los sistemas de regulación y control necesarios para que se puedan mantener las condiciones de diseño previstas en los locales climatizados, ajustando a la vez los consumos de energía a las variaciones de la demanda térmica, así como interrumpir el servicio; d) equipar las instalaciones con sistemas de contabilización del consumo energético en caso de instalaciones colectivas; e) incorporar subsistemas que permitan el ahorro, la recuperación de energía y el aprovechamiento de energías residuales; y f) utilizar energías renovables para cubrir una parte de las necesidades del edificio.

En sintonía con los Objetivos de Desarrollo Sostenible de las Naciones Unidas (Agenda 2030 para el Desarrollo Sostenible, 2015), la UE avanza hacia un modelo edificatorio "de consumo energético casi nulo" que rebasa el propósito de la eficiencia energética para lograr resultados mucho más ambiciosos. La Directiva 2010/31/UE utiliza ese concepto para referirse a los edificios con un nivel muy alto de eficiencia energética, caracterizada por el bajo consumo y su satisfacción a través de fuentes de energía renovables. El RD 56/2016, de 12 de febrero, por el que se traspone la Directiva 2012/27/UE, relativa a la eficiencia energética, en lo referente a auditorías energéticas, acreditación de proveedores de servicios y auditores energéticos y promoción de la eficiencia del suministro de energía, introduce en el ordenamiento español la definición de la Directiva, aunque sin establecer medidas de eficiencia que puedan facilitar la mejora de la calificación energética de los edificios. ${ }^{35}$ El art. 9 de la Directiva de 2010 ordena

\footnotetext{
${ }^{35}$ Su DA 4 a dispone: "Se define como edificio de consumo de energía casi nulo, en el ámbito de la Directiva 2010/31/UE del Parlamento Europeo y del Consejo, de 19 de mayo de 2010, relativa a la eficiencia energética de los edificios, aquel edificio con un nivel de eficiencia energética muy alto, que se determinará de conformidad con el anexo I de la citada Directiva. La cantidad casi nula o muy baja de energía requerida debería estar cubierta, en muy amplia medida, por energía procedente de fuentes renovables, incluida energía procedente de fuentes renovables producida in situ o en el entorno."
} 
a los estados miembros que, como muy tarde el 31 de diciembre de 2020, todos los edificios nuevos sean edificios de consumo de energía casi nulo. En el caso de edificios nuevos que estén ocupados y sean propiedad de autoridades públicas, esta exigencia se adelanta hasta el 31 de diciembre de $2018 .{ }^{36}$ Aunque se está trabajando en la buena dirección (compromiso con el Acuerdo de París de 2015, cumplimiento del primer periodo de compromiso del Protocolo de Kioto, impulso de las renovables, etc.), no parece que España pueda cumplimentar esta exigencia en plazo, muy probablemente por la tardanza en reaccionar a las exigencias comunitarias, dado que la transposición de las directivas energéticas se ha completado mucho más tarde de lo requerido. Así lo ha puesto palmariamente de relieve la Recomendación (UE) 2016/1318 de la Comisión, de 29 de julio de 2016, sobre las directrices para promover los edificios de consumo de energía casi nulo y las mejores prácticas para garantizar que antes de que finalice 2020 todos los edificios nuevos sean edificios de consumo de energía casi nulo. ${ }^{37}$

En 2013, el Ministerio de Fomento lanzó un Plan Integral de Vivienda y Suelo con el que se pretendía, a través de distintas iniciativas legislativas, ${ }^{38}$ mejorar el estado de conservación, la accesibilidad, la calidad, la sostenibilidad y la eficiencia energética del parque de viviendas y facilitar la reconversión y reactivación del sector de la construcción. En aplicación de dicho Plan se aprobó

\footnotetext{
${ }^{36}$ Dichos plazos se reiteran (aunque con un cierto desajuste temporal ya que la normativa interna fija la obligación más allá de la fecha límite) en la DA $2^{a}$ del RD 235/2013, de 5 de abril, por el que se aprueba el procedimiento básico para la certificación de la eficiencia energética de los edificios, modificado por el RD 564/2017, de 2 de junio. Esta norma considera como edificio de consumo de energía casi nulo aquel que cumple con los requisitos para edificios de nueva construcción en el Documento Básico DB-HE Ahorro de Energía.

37 Según la Directiva, "Esos avances se han producido hasta hoy con lentitud y deben ahora acelerarse. Si bien es cierto que han aumentado a nivel nacional las medidas destinadas a impulsar el número de edificios con un consumo de energía casi nulo, los Estados miembros deben redoblar sus esfuerzos para garantizar que en las fechas límite previstas en la Directiva todos los edificios nuevos tengan ya ese nivel de consumo" (Considerando $9^{\circ}$ ). Uno de los aspectos más destacados de estas recomendaciones es la indicación de que la finalización de un edificio puede resultar incierta y sufrir retrasos. Por lo tanto, se demanda que los estados miembros intervengan en el periodo de validez de las licencias de construcción, en la duración de las obras de edificación y en la aplicación de los objetivos de la Directiva con objeto de poder respetar la obligación de garantizar que, como muy tarde en enero del 2021, todos los edificios nuevos sean edificios de consumo de energía casi cero (Institut Català de l'Energia, 2017: p. 25). 38 Proyecto de L3R, Plan Estatal de Fomento del Alquiler de Viviendas, Rehabilitación Edificatoria y Regeneración y Renovación Urbanas (2013-2016), Proyecto de Ley de Medidas de Flexibilización y Fomento del Mercado del Alquiler de Viviendas y transposición de las directivas europeas sobre certificación de eficiencia energética.
} 
la L3R, ${ }^{39}$ la cual, tomando el testigo de la Ley $8 / 2007$, de 28 de mayo, de Suelo -que intentó virar modestamente hacia la sostenibilidad-, auspiciaba un modelo urbanístico alternativo más sostenible e inclusivo, en contraposición al modelo expansivo y transformador de suelos vírgenes que había monopolizado las actuaciones urbanísticas durante décadas y que ha contribuido a crear ciudades dispersas, poco funcionales y generadoras de una intensa repercusión ambiental (Quintana López, 2016: p. 17). ${ }^{40}$ El cambio de tendencia se hizo efectivo con la potenciación de las actuaciones de regeneración y renovación en el medio urbano y la rehabilitación edificatoria que, entre otras finalidades, fomentan la sostenibilidad en aras de mejorar la eficiencia, reducir los consumos energéticos y promover energías limpias. Esta Ley establece la regulación básica del informe de evaluación de edificios, en el que se integra la certificación de la eficiencia energética del edificio (art. 4). En otro orden de cosas, también se dispone que cuando no exista ninguna otra opción técnicamente viable y se consiga reducir al menos un $30 \%$ de la demanda energética anual de calefacción o refrigeración del edificio, se permite ocupar las superficies de espacios libres o de dominio público para realizar obras que consistan en la instalación de aislamiento térmico o fachadas ventiladas por el exterior del edificio, el cerramiento o acristalamiento de las terrazas ya techadas, la instalación de dispositivos bioclimáticos adosados a las fachadas o cubiertas y la implantación de instalaciones para la centralización o dotación de instalaciones energéticas comunes y de captadores solares $u$ otras fuentes de energía renovables en las fachadas o cubiertas (art. 10.4).

Paralelamente al diseño de este acervo normativo específico representado fundamentalmente por la LOE, su normativa de desarrollo y la legislación urbanística y de suelo y rehabilitación urbana, ${ }^{41}$ la Administración estatal ha impulsado una multiplicidad de planes, programas, estrategias y acciones que

\footnotetext{
39 La Disposición Derogatoria Única b) del RDLeg 7/2015, de 30 de octubre deroga los artículos 1 a 19 , las DA $1^{\underline{a}}$ a $4^{a}$, las DT $1^{\underline{a}}$ y $2^{\underline{a}}$ y las DF $12^{\underline{a}}$ y $18^{\underline{a}}$ de la Ley $8 / 2013$, así como las DF $19^{\underline{a}}$ y $20^{\mathrm{a}}$ de dicha ley, en la parte referida a alguno de los preceptos que se derogan.

40 La bibliografía sobre el cambio de modelo urbanístico producido con la L3R es muy extensa, puede consultarse, por todos, Gifreu Font, "Un cambio de rumbo en las políticas de suelo y urbanísticas: la mudanza del urbanismo expansivo y el redescubrimiento de la ciudad consolidada", en Cuadernos de Derecho Local, núm. 33, 2013, p. 30-55.

${ }^{41}$ Los requisitos europeos de eficiencia energética en la edificación también han encontrado acomodo en normas no vinculadas al sector de la edificación o el urbanismo, como la Ley 18/2014, de 15 de octubre, de aprobación de medidas urgentes para el crecimiento, la competitividad y la eficiencia.
} 
involucran al ahorro y la eficiencia energética desde distintos frentes. ${ }^{42}$ Con el fin de movilizar inversiones en la renovación del parque nacional de edificios residenciales y comerciales de titularidad pública y privada, el Ministerio de Fomento elaboró una "Estrategia a largo plazo para la rehabilitación energética en el sector de la edificación en España" (ERESEE 2014) así como su actualización (ERESEE 2017), en cumplimiento del art. 4 de la Directiva 2012/27/UE. Esta Estrategia, cuya renovación se realiza cada 3 años, establece la hoja de ruta, criterios y prioridades para las actuaciones de rehabilitación en nuestro país y para ello incorpora: a) un panorama del parque inmobiliario nacional, b) una definición de enfoques rentables de renovación en función de la tipología edificatoria y la zona climática, c) políticas y medidas destinadas a estimular renovaciones exhaustivas y rentables, d) una perspectiva de futuro para orientar las decisiones de inversión de particulares, industrias y entidades financieras y e) un cálculo del ahorro energético y de los beneficios que se esperan obtener. La estrategia española incluye una valoración técnica del parque de edificios y de las oportunidades de ahorro energético y señala la importancia estratégica de la renovación de edificios, incluido el vínculo con una regeneración urbana más amplia. En este sentido, la rehabilitación de edificios se considera un componente clave para mejorar las condiciones económicas, reactivar el sector de la construcción y revitalizar las zonas urbanas. ${ }^{43} \mathrm{La}$

\footnotetext{
42 Además de colaborar en las iniciativas estatales, las comunidades autónomas han dictado normativa propia, como la Ley 7/2017, de 14 de diciembre, de medidas de la eficiencia energética y garantía de accesibilidad a la energía eléctrica de Galicia, y han elaborado planes propios de eficiencia y ahorro energético, como el Plan de Ahorro y Eficiencia Energética en los edificios y equipamientos de la Generalitat de Catalunya 2015-2017 y el Plan de Ahorro y Eficiencia energética en edificios públicos de la Comunidad de Madrid (2017).

43 The Buildings Performance Institute Europe (BPIE), Renovation Strategies of Selected EU Countries. A Status Report on Compliance with Article 4 of the Energy Efficiency Directive, 2014, p. 53. Entre los objetivos específicos de la Estrategia se establecen unos de carácter cuantitativo y otros cualitativos. En relación con los objetivos cuantitativos, la Estrategia apunta tres escenarios diferentes de ahorro de los consumos de energía final para edificación residencial (ahorro en el consumo de energía final para usos térmicos -calefacción, refrigeración y ACSacumulado para el periodo $2014-2020$ igual al 32\%, 26\% y 7\% del consumo de energía final total) y dos escenarios para la edificación no residencial (ahorro acumulado para el periodo 2014-2020 igual al $20 \%$ y $16 \%$ del consumo de energía final total). En cuanto a los objetivos cualitativos, pueden citarse, entre otros, la formación de un marco normativo idóneo para hacer viable técnica, jurídica y económicamente- la rehabilitación edificatoria, la regeneración y la renovación urbanas; facilitar a los propietarios el cumplimiento del deber de conservación en los edificios, buscando las sinergias con la rehabilitación energética; la reducción de la factura energética de las familias y del país en su conjunto, así como la dependencia energética con el exterior; la apuesta por la regeneración urbana "integrada", con medidas técnico-urbanísticas, sociales, económicas y medioambientales en el ámbito de actuación correspondiente; y la reactivación del sector inmobiliario, de la construcción y sus industrias auxiliares, ofreciendo nuevas
} 
actualización de la ERESEE en 2017 analiza el impacto de las medidas de impulso de la eficiencia energética en el sector de la edificación puestas en práctica antes de 2014 y durante el período 2014-17, valorando su implementación y proponiendo, bien un mayor impulso de las existentes o bien nuevas medidas y ejes de acción aunque, a diferencia de la Estrategia de 2014, esta actualización no ha sido valorada muy positivamente. ${ }^{44}$

Entre los planes remitidos a la Comisión Europea en cumplimiento de los compromisos comunitarios figura el Plan Nacional de Acción de Eficiencia Energética 2017-2020, que da continuidad a los anteriores Planes de Acción 2011-2020 y 2014-2020, y que aborda, entre otras cuestiones, las distintas medidas de eficiencia energética desplegadas en el sector de la edificación (Ministerio de Energía, Turismo y Agenda Digital, 2017: p. 92 y ss.). En el ámbito legislativo, la actividad se ha centrado en la transposición de la Directiva 2010/31/UE mediante una serie de normas reglamentarias y en habilitar programas informáticos de calificación energética para edificios nuevos (Herramienta Unificada LIDERCALENER, HULC) y existentes (CE3 y CE3X). También se han desplegado medidas de contenido económico, como son los diversos programas de fomento de actuaciones para favorecer el ahorro energético, la mejora de la eficiencia energética, el aprovechamiento de las energías renovables y la reducción de las emisiones de CO2 así como el impulso a las empresas de servicios energéticos (BIOMCASA II, GEOTCASA, SOLCASA, GIT, Fondo JESSICA-FIDAE, Plan PIMA SOL, Programa PAREERCRECE, etc.), algunos de ellos cofinanciados con el Fondo Europeo de Desarrollo Regional (FEDER).

Los instrumentos económicos y financieros utilizados para optimizar la eficiencia energética de los edificios pueden ser muy diversos. En los estados miembros de la UE proliferan los contratos de rendimiento energético, las obligaciones de

oportunidades de desarrollo. Ministerio de Fomento, Estrategia a largo plazo para la rehabilitación energética en el sector de la edificación en España en desarrollo del artículo 4 de la Directiva 2012/27/UE, 2014, p. 32-35.

${ }^{44}$ BPIE, A snapshot of National Renovation Strategies. Examples from selected EU Member States. Briefing, 2017, p. 11. Entre las razones esgrimidas figuran la falta de actualización del parque de edificios existentes en cuestiones de censo y consumo de energía, la no concreción de las medidas propuestas en la estrategia 2014 (como los enfoques rentables de la rehabilitación y las políticas y medidas puestas en marcha para estimular la renovación profunda del sector de la construcción), el somero análisis de las necesidades de inversión y la ausencia de nuevas fuentes de financiación y de opciones de financiación. 
eficiencia energética y los certificados de rendimiento energético (Parejo Navajas, 2018: p. 358-359). El más común es el certificado de rendimiento energético, un documento que contiene información sobre la eficiencia energética del edificio o parte del mismo y al que se dedica el siguiente apartado de este trabajo. En cuanto a los contratos de rendimiento energético, constituyen una modalidad contractual en virtud de la cual el contratista (normalmente, una empresa de servicios energéticos) se compromete a ejecutar y financiar un conjunto de actuaciones para mejorar el rendimiento energético de un edificio y sus instalaciones y reducir su consumo de energía, manteniendo los niveles de servicio y confort del inmueble. ${ }^{45}$ El servicio incluye la auditoría energética del inmueble y el diseño y ejecución del proyecto integral de eficiencia energética, que puede incluir o no el uso de renovables, así como su supervisión y la medición y verificación de los ahorros del proyecto. Los costes del proyecto, incluidos los derivados de la inversión, se amortizan mediante el flujo de ingresos generados por el ahorro de los costes de funcionamiento (consumo energético, agua, etc.). Es, pues, la empresa de servicios energéticos la que asume el riesgo del rendimiento del proyecto durante la construcción y el periodo de ahorros garantizados sobre la base de los ahorros de costes acordados en el contrato (Institute for Building Efficiency, 2010: p. 4). En los últimos años, esta forma de contratación pública verde ha ganado adeptos entre las administraciones públicas puesto que no comporta un incremento del gasto público en la medida que es la empresa contratista la que realiza las inversiones. De esta forma, la Administración ahorra en el gasto de suministros energéticos y mejora la eficiencia de sus inmuebles a cuenta de la empresa (Román Márquez, 2017: p. 118). Por último, las obligaciones de eficiencia energética son un mecanismo en virtud del cual se asigna a las partes (empresas comercializadoras de gas y electricidad, operadores de productos petrolíferos al por mayor...) una cuota anual de ahorro energético denominada "obligación de ahorro". El certificado que

\footnotetext{
45 El contrato de rendimiento energético se define como "todo acuerdo contractual entre el beneficiario y el proveedor de una medida de mejora de la eficiencia energética, verificada y supervisada durante toda la vigencia del contrato, en el que las inversiones (obras, suministros o servicios) en dicha medida se abonan respecto de un nivel de mejora de la eficiencia energética acordado contractualmente o de otro criterio de rendimiento energético acordado, como, por ejemplo, el ahorro financiero" (art. 2.27 de la Directiva 2012/27/UE). El contratista asume, pues, un riesgo económico ya que el beneficio de la operación se hace depender del ahorro energético que se consiga con las actuaciones que lleve a cabo.
} 
acredita el nivel de ahorro energético obtenido puede ser comercializado por las empresas que hayan alcanzado un nivel de ahorro superior al del objetivo establecido legalmente. ${ }^{46}$

Los planes estatales de vivienda son otra de las herramientas que incluyen líneas de ayuda orientadas al fomento de la rehabilitación de edificios de viviendas con fines de mejora energética. El Plan Estatal de Vivienda y Rehabilitación 2009-2012 (RD 2066/2008, de 12 de diciembre) previó ayudas para la mejora de la eficiencia energética, la integración de energías renovables y para asegurar la estanqueidad del edificio. El Plan Estatal de fomento del alquiler de viviendas, la rehabilitación edificatoria y la regeneración y renovación urbana, 2013-2016 (RD 233/2013, de 5 de abril) contemplaba un programa para la rehabilitación energética que subvenciona las actuaciones que reduzcan al menos en un $30 \%$ la demanda energética anual global de calefacción y refrigeración del edificio. El vigente Plan Estatal de Vivienda 2018-2021 (RD 106/2018, de 9 de marzo) insiste en el fomento de la mejora de la eficiencia energética y la sostenibilidad en viviendas, mediante un Programa específico cuyo objeto es la financiación de obras que persigan esa finalidad, con especial atención a la envolvente edificatoria en edificios de tipología residencial colectiva, incluyendo sus viviendas, y en las viviendas unifamiliares (art. 33).

Otro instrumento habitual para movilizar y promocionar las inversiones en la renovación energética de edificios son los incentivos fiscales. De conformidad con el art. 91.2 de la Ley 37/1992, de 28 de diciembre, del Impuesto sobre el Valor Añadido, las obras de rehabilitación tributan al tipo reducido del $10 \%$ del IVA cuando concurran determinados requisitos. ${ }^{47}$ Por su parte, el art. 103.2.b) del RDLeg 2/2004, de 5 de marzo, por el que se aprueba el texto refundido de la Ley Reguladora de las Haciendas Locales, prevé la aplicación de una bonificación de hasta el 95 \% (de aplicación potestativa por los municipios) a

\footnotetext{
46 Vid. la Ley 18/2014, de 15 de octubre, de aprobación de medidas urgentes para el crecimiento, la competitividad y la eficiencia, que establece un sistema nacional de obligaciones de eficiencia energética.

${ }^{47}$ Para la aplicación de tipo reducido, la Agencia Tributaria exige que más del $50 \%$ del coste total del proyecto de rehabilitación se corresponda con obras de consolidación o tratamiento de elementos estructurales, fachadas o cubiertas o con obras análogas o conexas a las de rehabilitación (entre las obras conexas se sitúa la rehabilitación energética) y el importe de las obras exceda del $25 \%$ del precio de la vivienda.
} 
favor de las construcciones, instalaciones $u$ obras en las que se incorporen sistemas para el aprovechamiento térmico o eléctrico de la energía solar. ${ }^{48}$

En un reciente informe, la Comisión de Expertos de Transición Energética considera que la eficiencia energética en el sector residencial ha mejorado en los últimos años "pero para alcanzar en el año 2050 un alto nivel de descarbonización en la edificación será necesaria la reconversión energética del parque existente, priorizando los proyectos en los que la diferencia entre la inversión y el valor actual de los ahorros futuros de energía asociados sea mayor. En el diseño de medidas de apoyo, es necesario permitir que el consumidor pueda elegir la alternativa más eficiente e incluir criterios en relación con los consumidores más vulnerables". ${ }^{49}$ Con estos propósitos en el horizonte, se realizan una serie de recomendaciones en materia de ahorro y eficiencia energética en la edificación, como son: a) a nivel normativo, revisar el CTE, concretar la normativa de los edificios de consumo casi nulo, avanzar en la obligatoriedad de la certificación energética de todos los edificios y mejorar el etiquetado de los equipos; b) realizar un diagnóstico del avance de la estrategia 2014-2020 de rehabilitación y regeneración energética urbana y establecer una nueva estrategia al horizonte 2030 con visión 2050; c) descarbonizar el sector de la edificación priorizando la reducción del consumo y la progresiva electrificación, mediante el autoconsumo eléctrico y las renovables eléctricas a nivel centralizado; además, una parte importante del consumo final no eléctrico debería ser suministrado por fuentes renovables térmicas in situ, a lo que contribuiría la promoción de sistemas centralizados de redes de calor de alto rendimiento; d) ampliar el ámbito de intervención de las Administraciones Públicas más allá de los edificios, incluyendo también el alumbrado público, así como la sustitución de flotas de transporte público y del parque móvil con vehículos que utilicen energías alternativas; y e) establecer nuevos mecanismos de financiación, distintos de los tradicionales y más acordes a la vida útil de este tipo de medidas e impulsar sistemas de financiación complementarios, vía bonificaciones fiscales y aprovechar la guía de Eurostad sobre el cómputo de

\footnotetext{
48 Para un análisis del fomento de actuaciones de eficiencia energética desde la perspectiva tributaria, vid. Villca Pozo, "Incentivos fiscales para fomentar actuaciones de mejora en la eficiencia energética de viviendas de construcción antigua", en Revista Catalana de Dret Ambiental, vol. III (2), 2017, p. 1-22.

${ }^{49}$ Comisión de Expertos de Transición Energética, Análisis y propuestas ..., cit., p. 35.
} 
estas actuaciones a efectos de la Contabilidad Nacional como instrumento para la mejora de la eficiencia energética.

\section{b) El certificado de eficiencia energética de los edificios}

La acreditación del grado de eficiencia energética de los edificios viene exigida sucintamente en el Texto Refundido de la Ley de Suelo y Rehabilitación Urbana, aprobado por RDLeg 7/2015, de 30 de octubre, como trasunto de la L3R. ${ }^{50}$ Dicho requerimiento se inscribe en el contexto de la regulación básica del informe de evaluación de los edificios, un instrumento de intervención administrativa con triple funcionalidad, puesto que fiscaliza tanto el estado de conservación del inmueble como su accesibilidad y eficiencia energética. ${ }^{51}$ Este documento representa una evolución respecto de las tradiciones inspecciones técnicas del edificio (ITE), vinculadas exclusivamente al deber de conservación y mantenimiento de los propietarios de inmuebles, un deber previsto inicialmente en la legislación preconstitucional estatal y, posteriormente, en las ordenanzas locales y las normas urbanísticas autonómicas. ${ }^{52}$ El Preámbulo de la L3R dispone que el informe de evaluación de los edificios debe incluir un apartado orientativo sobre la eficiencia energética de los edificios y el cumplimiento de los compromisos de España con Europa en el horizonte 2020. La Directiva 2010/31/UE "exige que esta certificación se adjunte cuando una vivienda se ponga en venta o en alquiler, en aras de una mayor transparencia del mercado, una mayor información para los propietarios y un menor coste en su emisión, se busca la doble racionalidad y sinergia que supone incluirla en el informe de evaluación del edificio".

Esta regulación ha sido decapitada por la STC 143/2017, de 14 de diciembre,

\footnotetext{
50 Para profundizar en el régimen jurídico de la certificación energética de edificios, vid., sin ánimo de exhaustividad, Casares Marcos, "Informe de evaluación de edificios y eficiencia energética", en Revista Jurídica de Castilla y León, núm. 39, 2016.

51 El enfoque integrador del informe de evaluación de edificios puede ayudar a incrementar las rehabilitaciones energéticas: "En definitiva, se trataría de aprovechar la teoría del 'ya que...', que ha demostrado ser efectiva y que consiste en vincular las rehabilitaciones que los ciudadanos sí que consideran de interés o necesarias, como es una intervención para eliminar barreras arquitectónicas, reparar humedades, etc. a otras que no son tan solicitadas por desinformación fundamentalmente de los ciudadanos, como son la rehabilitación energética" (Serrano Lanzarote y Sanchís Cuesta, 2015: p. 5).

52 Puesto que la inspección técnica de edificios no había sido establecida por todas las comunidades autónomas, el RD-ley 8/2011, de 1 de julio, generalizó su obligatoriedad en todo el territorio nacional (Fernández de Gatta Sánchez, 2016: p. 387).
} 
que ha anulado, por inconstitucionales, cinco apartados del art. 29 ("Informe de Evaluación de los Edificios") y el art. 30 en su totalidad ("Capacitación para suscribir el Informe de Evaluación de los Edificios"), ${ }^{53}$ manteniendo únicamente el art. 29.1, a tenor del cual los propietarios de inmuebles ubicados en edificaciones con tipología residencial de vivienda colectiva pueden ser requeridos por la Administración competente para que acrediten la situación de dichos inmuebles mediante la presentación de un informe de evaluación del edificio (IEE). ${ }^{54}$ Como se ha apuntado, este documento conforma en realidad un triple informe dado que contiene información sobre el estado de conservación del edificio y el cumplimiento de la normativa vigente sobre accesibilidad universal (equivalente a una inspección técnica del edificio), así como sobre el grado de eficiencia energética de éste. Se constituye así en un instrumento clave de sostenibilidad ambiental urbana (Casares Marcos, 2016: p. 34-35).

Según el Tribunal Constitucional, el Estado únicamente ostenta competencias para regular el certificado de eficiencia energética (legislación básica sobre protección del medio ambiente y bases del régimen energético, ex. art. 149.1, apartados $23^{\circ}$ y $2^{\circ}$, CE), puesto que la evaluación del estado de conservación del edificio y de las condiciones de accesibilidad forma parte de la inspección urbanística y es patrimonio competencial autonómico, debiendo regirse el IEE por la normativa de las comunidades autónomas y por las ordenanzas municipales, allí donde existan. Así, por ejemplo, el Decreto catalán 67/2015, de 5 de mayo, para el fomento del deber de conservación, mantenimiento y rehabilitación de los edificios de viviendas mediante las inspecciones técnicas y el libro del edificio, regula el "Informe de la inspección técnica de los edificios de viviendas" (IITE) en tanto que documento que describe las características generales del edificio, su estado de conservación y las posibles deficiencias aparentes constructivas o funcionales que pueden afectar a los elementos

\footnotetext{
${ }^{53}$ La STC 143/2017, de 14 de diciembre, se dicta en respuesta al recurso de inconstitucionalidad interpuesto por la Generalitat de Cataluña en relación con diversos preceptos de la L3R (que se proyectan sobre los preceptos equivalentes del Texto Refundido de 2015) y sigue la estela de la STC 5/2016, de 21 de enero, que declaró inconstitucionales los arts. 21 y 22 , la DA $3^{\underline{a}}$ y las DT $1^{\text {a }}$ y $2^{a}$ del RD-ley $8 / 2011$, relativos a la inspección técnica de edificios.

${ }^{54}$ En relación con el técnico competente para emitir el informe de evaluación de edificios, vid. Gifreu Font, "El deber legal de conservación y rehabilitación de los propietarios de viviendas: la inspección técnica de edificios en Cataluña y la concreción del técnico facultativo competente para calificar el estado general de conservación”, en Práctica Urbanística, núm. 137, 2015, p. 96 yss.
} 
comunes y su calificación. También contiene las propuestas que se aconsejan técnicamente para la mejora de la sostenibilidad, la ecoeficiencia, ${ }^{55}$ la funcionalidad y las condiciones de accesibilidad del edificio. Esta inspección es obligatoria en los edificios unifamiliares o plurifamiliares, donde exista el uso de vivienda, sin perjuicio de que puedan también incluir otros usos diferentes del residencial. No es de aplicación a los edificios unifamiliares en los que su edificación principal, excluidas construcciones auxiliares de escasa entidad constructiva, esté separada 1,5 metros o más de la vía pública, de zonas de uso público y de las fincas adyacentes. ${ }^{56}$

La Directiva 2010/31/UE establece -como ya señalaba la Directiva 2002/91/UEla obligación de poner a disposición del posible comprador o arrendatario de un edificio o de alguna unidad del mismo una certificación energética que ofrezca información correcta acerca de su eficiencia energética, del impacto real de la calefacción y la refrigeración en las necesidades de energía del edificio, de su consumo de energía primaria y de sus emisiones de dióxido de carbono, así como recomendaciones de mejora (Considerando $22^{\circ}$ de la Directiva 2010/31/UE). La nueva redacción dada por la Directiva 2018/488 al art. 20.2 establece que los estados miembros deben informar a los propietarios o a los arrendatarios de los edificios sobre los certificados de eficiencia energética, incluidos su finalidad y objetivos, sobre las medidas rentables y, cuando proceda, los instrumentos financieros para mejorar la eficiencia energética del edificio y sobre el remplazo de las calderas de combustibles fósiles por alternativas más sostenibles.

El certificado de eficiencia energética es una herramienta útil para comprobar el "estado energético" del parque inmobiliario nacional. Se trata de un documento

\footnotetext{
55 Cabe recordar que el derogado art. 29.2.c) disponía que cuando de conformidad con la normativa autonómica o municipal, exista un Informe de Inspección Técnica que evalúe el estado de conservación y la accesibilidad, se podrá complementar con la certificación de eficiencia energética, con los mismos efectos que el IEE.

${ }^{56}$ Las comunidades autónomas han regulado las condiciones de registro, resolución, silencio administrativo, etc. de la certificación energética de edificios. Es el caso, por ejemplo, de Extremadura (Decreto 136/2009, de 12 de junio); Valencia (Decreto 112/2009, de 31 de julio); Canarias (Decreto 26/2009, de 3 de marzo); Navarra (Orden foral 7/2010, de 21 de enero); Castilla y León (Decreto 55/2011, de 15 de septiembre); Castilla-La Mancha (Decreto 6/2011, de 1 de febrero); País Vasco (Decreto 226/2014, de 9 de diciembre); Andalucía (Orden de 9 de diciembre de 2014), Galicia (Decreto 128/2016, de 25 de agosto) y Asturias (Resolución de 28 de diciembre de 2017, de la Consejería de Empleo, Industria y Turismo, de tercera modificación de la Resolución de 29 de diciembre de 2015).
} 
suscrito por técnico competente que contiene información sobre las características energéticas y la calificación de eficiencia energética. Su finalidad es eminentemente informativa, y no solo en beneficio de los consumidores, puesto que, con los datos que arrojan el conjunto de las certificaciones emitidas, el estado español puede calibrar la efectividad de las políticas que está aplicando y si está en disposición de alcanzar los objetivos de la Directiva 2012/27/UE para 2020. El procedimiento básico para la expedición de la certificación energética de los edificios se regula en el RD 235/2013, de 5 de abril. ${ }^{57}$ A su tenor, la certificación energética es exigible desde el 1 de junio de 2013 en relación con los edificios de nueva construcción, los edificios existentes o partes de éstos que se vendan o alquilen a un nuevo arrendatario y los edificios o partes de los mismos ocupados por una autoridad pública en más de $250 \mathrm{~m}^{2}$ y frecuentados habitualmente por el público. ${ }^{58}$ El certificado de eficiencia energética debe incluir información objetiva sobre la eficiencia energética de un edificio (envolvente térmica, confort lumínico, calidad del aire interior, etc.) y valores de referencia tales como requisitos mínimos de eficiencia energética con el fin de que los propietarios o arrendatarios del edificio puedan comparar y evaluar su grado de eficiencia. 59

La calificación de la eficiencia energética de un edificio se determina mesurando el consumo de energía que se requiere para satisfacer la demanda energética anual del edificio en condiciones normales de funcionamiento y ocupación, asociadas a unas condiciones climáticas determinadas. El nivel de eficiencia puede expresarse de forma cualitativa o cuantitativa mediante indicadores, índices o una escala de letras. La metodología de cálculo de la eficiencia energética se contiene en el documento Calificación de la eficiencia energética de los edificios de conformidad con el RD 235/2013. Esta calificación se expresa mediante una etiqueta energética, que utiliza una valoración que va desde la

\footnotetext{
${ }^{57}$ Las exigencias de la Directiva 2002/91/CE se transpusieron en el RD 47/2007, de 19 de enero, mediante el que se aprobó un Procedimiento básico para la certificación de eficiencia energética de edificios de nueva construcción. Tras la modificación de la Directiva 2002/91/UE en 2010, el Gobierno español aprobó el RD 235/2013 de 5 de abril, que transpone parcialmente la Directiva 2010/31/UE y deroga el RD de 2007. Este RD ha sido objeto de modificación mediante el RD $564 / 2017$, de 2 de junio.

58 EI RD 564/2017 modifica el art. 2.2 del RD 235/2013 para excluir determinados edificios del procedimiento básico para la certificación energética.

59 Estos requisitos mínimos, como hemos comentado, se encuentran establecidos en el CTE, actualmente en proceso de revisión. Vid. el art. 6 del RD 235/2013, que establece el contenido mínimo del certificado de eficiencia energética.
} 
clase A (mayor eficiencia) hasta la $G$ (menor eficiencia). Los indicadores principales de eficiencia energética se refieren a las emisiones anuales de CO2 y al consumo anual de energía primaria no renovable, que incluyen el impacto de los servicios de calefacción, refrigeración, producción de agua caliente sanitaria y, en usos distintos al residencial privado, de iluminación, así como la reducción de emisiones o consumo de energía primaria no renovable derivada del uso de fuentes de energía renovables. En cuanto a los indicadores complementarios, estos son la demanda energética anual de calefacción, la demanda energética anual de refrigeración, el consumo anual de energía primaria no renovable desagregada por servicios, las emisiones anuales de $\mathrm{CO} 2$ desagregada por servicios, y las emisiones anuales de $\mathrm{CO} 2$ desagregada por consumo eléctrico y por otros combustibles. ${ }^{60}$

El promotor o propietario del edificio es el responsable de encargar la realización de la certificación de eficiencia energética del edificio en los casos en que venga obligado (art. 5 RD 235/2013). El incumplimiento de las obligaciones relacionadas con la eficiencia energética por parte del promotor, propietario 0 arrendatario comporta la imposición de una sanción económica que se cifra entre los 300 y 6000 euros y que podrá elevarse hasta el importe efectivo del beneficio obtenido por el infractor (DA 12 ${ }^{\underline{a}}$ y $13^{\text {a }}$ RDLeg 7/2015).

Una vez obtenido, el certificado de eficiencia energética debe inscribirse en el registro habilitado por cada Comunidad Autónoma, la cual gestiona un sistema de control independiente de dichos certificados (resultados, recomendaciones, inspecciones...). Su obtención otorga al solicitante el derecho de utilizar la etiqueta de eficiencia energética durante el periodo de validez del mismo, que se fija en un máximo de 10 años. En todo caso, deben exhibir la etiqueta de eficiencia energética de forma obligatoria los edificios o unidades de edificios de titularidad privada con una superficie útil total superior a $500 \mathrm{~m}^{2}$ y los ocupados por autoridades públicas con una superficie útil total superior a $250 \mathrm{~m}^{2}$, en ambos casos cuando sean frecuentados habitualmente por el público. En el resto de supuestos, la exhibición pública de la etiqueta de eficiencia energética es voluntaria (art. 13).

${ }^{60}$ Ministerio de Industria, Energía y Turismo - IDAE, Calificación de la eficiencia energética de los edificios, 2015, p. 4. 


\section{UN CASO DE ESTUDIO: EFICIENCIA ENERGÉTICA E INTEGRACIÓN DE RECURSOS ENERGÉTICOS RENOVABLES MEDIANTE EL DISTRICT HEATING AND COOLING (XARXA ESPAVILADA) DE OLOT}

\section{Reducción del consumo energético y fomento de renovables mediante las redes de calor y frio}

La situación geográfica y las características socioeconómicas de nuestro país hacen que sea especialmente vulnerable al cambio climático, de manera que los proyectos innovadores que apuestan por la búsqueda de soluciones óptimas deben ser especialmente valorados. Uno de los objetivos más urgentes es la eficiencia energética, elemento fundamental de la estrategia europea para un crecimiento sostenible en el horizonte 2030 y para reducir las emisiones de gases de efecto invernadero. El sector energético presenta una relación de dependencia entre la temperatura y los consumos de combustibles en invierno, y de electricidad todo el año. La tendencia general es que se asista a la presencia de inviernos más cálidos, lo que puede suponer un descenso de la demanda energética de gas y electricidad, mientras que por otra parte se esperan veranos más calurosos, lo que seguramente provocará un incremento de la demanda de electricidad para refrigeración (FEMP/Coordinación de Acción Territorial y Desarrollo Sostenible /Red Española de Ciudades por el Clima, 2010: p. 104).

La cada vez más escasa cantidad de combustibles fósiles obliga a las ciudades a avanzar con premura en el proceso de transición energética mediante el desarrollo de energías sostenibles frente al mantenimiento de las tecnologías tradicionales. La descarbonización requiere una necesaria adaptación tecnológica, de ahí que el modelo de ciudad inteligente deba integrarse en las políticas climáticas locales. La tecnología para reducir el consumo energético y las fuentes de energía renovable son el arma más eficaz en la lucha contra el cambio climático, a la vez que representan un modelo económico más eficiente en el corto y largo plazo. Este modelo energético está llamado a crear un mercado de inversión, con oportunidades de negocio para las empresas locales, y generador de riqueza y ocupación en el territorio (generación y 
comercialización local de energía, construcción, telecomunicaciones, innovación tecnológica...). En el futuro, el suministro de energía de las ciudades en constante crecimiento únicamente podrá garantizarse con el recurso a fuentes renovables, de las cuales deberá hacerse un uso eficaz y eficiente, potenciando el autoconsumo. Y la ciudad es un espacio apropiado para experimentar con la generación de energía renovable, especialmente los edificios públicos o las áreas de suelo industrial con fuerte demanda de energía, que pueden convertirse asimismo en generadores potenciales de la misma. Un ejemplo de experiencia innovadora y sostenible son las redes de distrito o district heating and cooling (más conocidas por su acrónimo DHC).

Las redes de distrito de calor y frío conforman un sistema de climatización centralizado y comunitario que combina tecnologías eficientes y fuentes renovables. Más concretamente, el calor y el frío se producen en una central de generación y esa energía térmica producida se transporta y distribuye desde la central hasta los usuarios conectados al sistema, mediante un sistema de tuberías aisladas para minimizar las pérdidas térmicas. En consecuencia, los elementos esenciales de estas redes de calefacción y refrigeración urbana son la central de generación térmica, la red de tuberías de distribución y las subestaciones de conexión con los consumidores. La central de generación produce calor o frío de manera centralizada para los distintos consumidores, de modo que no hace falta contar con equipos individuales en los puntos de consumo -es decir, que el consumidor no debe disponer de ningún aparato que transforme en climatización la energía que recibe, ya se trate de edificios o de unidades del mismo-. Esta circunstancia permite disponer de tecnologías con mejor eficiencia energética como la cogeneración, el uso de calor residual o las energías renovables (biomasa, solar, geotermia), que son equipos más eficientes por factor de escala. Mediante una red de tuberías que acostumbran a distribuirse en zanjas subterráneas que siguen el trazado de las calles, la energía se transporta hasta los usuarios. El agua situada dentro de las tuberías actúa como fluido conductor de la energía: cuando llega a los usuarios, se cede el calor a los puntos de consumo, enfriando el fluido (en el caso de las redes de calefacción) o, a la inversa, se absorbe el calor de los puntos de consumo, calentando el fluido (en el caso de redes de refrigeración). La red dispone, asimismo, de un circuito de retorno a la central. La transferencia térmica entre la 
red de distribución y los consumidores se realiza a través de una subestación formada por un intercambiador y los elementos que regulan y controlan que el funcionamiento sea el correcto, así como los elementos de medición para facturar las energías (Institut Català d'Energia-ADHAC, 2011: p. 9). Las fuentes de energía que se utilizan habitualmente en las redes de distrito son la cogeneración (producción combinada de calor y electricidad), la valorización de residuos, las fuentes de origen renovable (solar, biomasa, geotérmica, biogás) y incluso el agua (marina, fluvial, freática).

Con las redes de distrito se mejora la eficiencia global del sistema de climatización de espacios (generación / demanda) mediante el uso de tecnología y energías renovables, lo que genera una reducción de la demanda energética. Estas redes de distrito que distribuyen frío y/o calor incrementan la eficiencia energética en la generación, integrando las energías renovables (biomasa, geotérmica, solar térmica, etc.), los recursos locales que de otra manera se perderían (enfriamiento natural, calor o frío sobrante de la industria cercana, la producción combinada de calor y frío, etc.), y los sistemas de producción de alta eficiencia. ${ }^{61} \mathrm{~A}$ pesar de los beneficios que presenta esta tecnología, la implantación de redes de distribución de calor y frío en España es aún muy minoritaria, a diferencia de lo que ocurre en el centro y norte de Europa, donde la producción de calor mediante esta tecnología tiene un peso importante, especialmente, en países como Islandia, Finlandia, Dinamarca y Suecia. ${ }^{62}$ En España son aún una minoría los ayuntamientos que cuentan con experiencias de este tipo, lejos de los más de 700 proyectos que se han implementado en Dinamarca. ${ }^{63}$ En el marco del programa Intelligent Energy Europe, se ha desarrollado el proyecto SmartReflex cuyo objetivo es incrementar las redes de

61 IDAE, Redes de calor y frio. En línea: http://www.idae.es/tecnologias/eficienciaenergetica/edificacion/redes-de-calor-y-frio (última consulta: 4 de septiembre de 2018).

62 Existen más de 5.000 sistemas de District Heating suministrando más del $9 \%$ de la demanda de energía útil en calor con una facturación anual de 19,5 billones de euros. La penetración en el mercado varía según los países, en algunos de los cuales puede alcanzar el $70 \%$. Institut Català d'Energia-ADHAC, Guía Básica ..., cit., p. 12.

${ }^{63}$ Con distintas dimensiones e intensidades, podemos citar las iniciativas de la Red Districlima de Barcelona (distritos Forum y 22@), Tub Verd de Mataró, Parc de l'Alba-Centro Direccional de Cerdanyola del Vallès, Cuéllar, Parque de Innovación Tecnológica de Mallorca, Ciudad Agroalimentaria de Tudela, Recinto ExpoZaragoza, la Granja de Molins de Rei, Sant Pere de Torelló, Tarragona, el barrio del Guinardó en Barcelona, FUNDOMA en Oviedo, Colmenar, Paracuellos, Alcalá de Henares, Cuenca, Ciudad Lineal, Guadalajara, Alcorcón, Orcásitas, Bellver de Cerdanya, las colonias municipales de San Francisco Javier y Nuestra Señora de los Ángeles en el Distrito de Puente de Vallecas de Madrid, etc. 
calor y frío inteligentes y flexibles mediante la utilización de un alto porcentaje de fuentes de energía renovable en las ciudades europeas. En el citado proyecto participan 6 regiones de 4 países (Dinamarca, Alemania, Irlanda y España), siendo Cataluña la región participante por España, con un grupo de trabajo liderado por el Instituto Catalán del Suelo y el Instituto de Investigación de la Energía de Cataluña. Cada grupo de trabajo es responsable de implementar medidas legislativas y organizativas para la promoción de redes de distrito que incluyen la mejora del marco legal regional, la integración de sistemas de redes de distrito en los planeamientos de calefacción a nivel regional y local, la creación de empresas cooperativas que gestionen estos sistemas y el apoyo a la creación de nuevas redes a nivel local. Entre el conjunto de medidas propuesto por el equipo SmartReflex catalán destaca la conveniencia de actualizar las normativas urbanísticas en materia energética con medidas como la de exigir que todos los instrumentos de planeamiento incluyan un estudio justificativo de la viabilidad de una red de distrito en los nuevos desarrollos urbanos y que, en caso de no ser viable, se garantice que las condiciones energéticas (eficiencia, rendimientos e incorporación de renovables) y medioambientales (control de emisiones) del sistema alternativo propuesto supongan una mejora respecto de las que aporte una red de distrito con fuentes renovables. Asimismo, se considera fundamental que los planes prevean el aprovechamiento de las energías residuales producidas en sectores de actividades económicas -y que a menudo acaban perdiéndose-con el fin de inventariarlas y fomentar su comercialización a través de las redes de distrito.

Las ventajas de contar con estos sistemas inteligentes de distribución de frío y calor son numerosas, desde la reducción del impacto ambiental y el consumo energético, pasando por la mejora de la calidad del espacio urbano y de su paisaje (eliminación de condensadores en fachadas y de torres de refrigeración), los beneficios económicos derivados del aprovechamiento de energías residuales y renovables autóctonas, la reducción del efecto de "islas de calor" por la eliminación de equipos energéticos individuales y sus emisiones asociadas, la producción local de electricidad y la creación de puestos de trabajo, entre otras. Asimismo, las redes de distrito trazan una nueva dimensión entre el urbanismo, la edificación y la energía en la medida que "contribuyen a descentralizar la generación en grandes plantas y a crear islas urbanas más 
autosuficientes; reducen los costes y precios finales de producción y consumo de la energía, e introducen cambios en los hábitos de las personas respecto al uso de los recursos energéticos, puesto que el consumo de calorías y frigorías en lugar de quilovatios o metros cúbicos de combustible favorece el ahorro y el uso más eficiente. Las actuales exigencias normativas europeas con relación al comportamiento energético de los edificios favorecerán, en los próximos años, esta nueva concepción del binomio ciudadano-energía". ${ }^{64}$

\section{El District Heating and Cooling (Xarxa Espavilada de climatización) de Olot 65}

\section{a) Cuestiones previas}

La comarca de la Garrotxa ${ }^{66}$ es un ejemplo de territorio concienciado con el cambio climático. Desde hace años, se ha convertido en un laboratorio de ideas y de implementación de iniciativas sostenibles y eficientes relacionadas con fuentes de energía renovables. Uno de los principales impulsores en la implementación de una nueva gestión ambiental es SIGMA (Consorcio de Medio Ambiente y Salud Pública de La Garrotxa), un ente público integrado por el Consejo Comarcal y el Ayuntamiento de Olot, que ostenta la capitalidad de la comarca. Además de llevar a cabo una gestión sostenible de servicios (residuos y limpieza viaria, ciclo del agua, espacios verdes y huertos urbanos...), SIGMA también desarrolla un número considerable de proyectos transversales, entre los que pueden citarse las iniciativas para afrontar situaciones de cambio y garantizar servicios básicos resilientes, minimizando las afectaciones.

Las administraciones públicas y el sector privado se han involucrado muy especialmente en el ámbito de la sostenibilidad energética. Para ello, empresas e instituciones han constituido una agrupación (Locomotora Energética) para lograr la generación de CO2 cero a largo plazo. La comarca cuenta además con un Programa de Energía de la Garrotxa 2010-2015: Plan de Energías

\footnotetext{
64 Institut Català d'Energia (ICAEN), "Editorial”, en Cultura Energètica, núm. 178, 2011, p. 2.

65 Quiero agradecer la ayuda prestada para la elaboración de este apartado al Sr. Francesc Canalias, director de SIGMA y al Sr. Franc Comino, socio fundador y CEO de Wattia Innova.

${ }^{66}$ Comarca de la provincia de Girona de relieve montañoso y con una zona volcánica situada en Olot, capital de la comarca (34.194 habitantes en 2017). Formada por 21 municipios, tiene una superficie de 734,62 km2 y una población de 56.184 habitantes (2017). Fuente: IDESCAT, 2018.
} 
Renovables, Estrategia de Ahorro y Eficiencia Energética (2011) en cumplimiento de las obligaciones del Pacto de los Alcaldes, al que están adheridos los 21 municipios que conforman el ámbito comarcal. También participa de las iniciativas vinculadas a la Red de Transición (Transition Network), que promueven el avance a un modelo sostenible de reducción drástica de emisiones de $\mathrm{CO} 2$. Entre sus últimos proyectos se cuenta la puesta en marcha de una prueba piloto única en Europa, el programa EuroPACE (por las siglas Property Assessed Clean Energy), aplicado con éxito en diversas ciudades de Estados Unidos.

Una de las iniciativas con mayor proyección internacional en las que SIGMA colabora con el Ayuntamiento de Olot ha sido la creación de una red de distrito o District Heating and Cooling en el centro de la ciudad, conocido como la "Xarxa Espavilada" (Red Inteligente). El proyecto ha obtenido distintos galardones nacionales: el Premio a la Excelencia Energética 2017 de la Generalitat de Cataluña y el Premio BBConstrumat 2017 en la categoría de obra construida por su interés como estrategia urbana para la mejora medioambiental. También ha recibido el premio de la European Heat Pump Association (Heat Pump City of the Year 2015), por su capacidad para integrar un sistema de bombas de calor geotérmicas en el casco antiguo de una ciudad. Es la primera vez que este reconocimiento recae en una ciudad del sur de Europa.

\section{b) La prueba piloto: EspaiZero}

La Directiva 2010/31/UE relativa a la eficiencia energética de los edificios dispone que todos los edificios de nueva planta deben tener un consumo energético casi nulo a partir del 31 de diciembre de 2020, si bien esta obligación se anticipa dos años en los edificios públicos. EspaiZero (EspacioCero) es una iniciativa pionera en España que, mediante una combinación de sistemas de producción, ha permitido disponer del primer edificio privado $100 \%$ autosuficiente en materia energética. ${ }^{67}$

La central energética se localiza en el local que funciona como sede social de la empresa promotora del proyecto, Wattia Innova SLU. Inaugurada en 2013, la

${ }^{67}$ EspaiZero ha sido declarado por Greenpeace y la Cátedra UNESCO como el primer centro de trabajo español de consumo cero. 
empresa es experta en la gestión automatizada y en la integración de los distintos sistemas energéticos involucrados. La filosofía que subyace en la iniciativa es concienciar sobre la necesidad de superar el modelo energético tradicional, basado en un único sistema de producción energética, y evolucionar a un sistema de energías limpias integradas.

Con este proyecto se suministra calor, frío y electricidad a una superficie de 200 m2 mediante un sistema de trigeneración de energías renovables que combina principalmente tecnología geotérmica, fotovoltaica y acumulación energética. EI sistema fotovoltaico funciona de forma autónoma, utilizando la energía que necesita y almacenando el sobrante en baterías, que disponen de una autonomía de 24 horas. También la geotermia -que produce energía eficiente para calentar y refrigerar y se distribuye por el suelo radiante (calor) o el techo refrescante (frío), como la electricidad o el agua- permite almacenar la energía remanente en pilas de agua que la producen en la franja horaria que resulta más económica.

El control y automatización del sistema es esencial, ya que se utiliza la energía más adecuada en cada momento en atención a diversas derivadas, como las condiciones meteorológicas y la generación potencial de energía.

\section{c) La Xarxa Espavilada como paradigma de alimentación energéticamente eficiente de un entorno urbano}

i. Ámbito de aplicación del proyecto y modelo de producción energética

La exitosa aplicación del modelo energético combinado en EspaiZero permitió afrontar un nuevo reto tecnológico: expandir la iniciativa a un plano superior, una isla energética en el centro histórico de la ciudad con consumo energético cero. Con la salvedad de que el nuevo proyecto se focaliza en la instalación de dos redes de calor y frío alimentadas en su totalidad por un sistema de renovables, pero no abastece la demanda de electricidad.

El Ayuntamiento de Olot licitó en 2014 un proyecto de isla energética para la ciudad. El 20 de febrero de 2014, el Pleno municipal aprobó el expediente de contratación para adjudicar, mediante procedimiento abierto, la concesión de obra pública para la construcción y servicio de mantenimiento integral de las instalaciones de una red de calor con uso de energías renovables y suministro 
de energía. ${ }^{68}$ En sesión extraordinaria de fecha 4 de julio de 2014, el órgano plenario adjudicó la concesión a la UTE formada por las empresas Gas Natural y Wattia Innova, con una serie de mejoras propuestas por esta. El contrato tiene una duración de 15 años, a contar desde la fecha de recepción definitiva de las obras, y una inversión económica de cerca de dos millones de euros.

La implementación del proyecto, que ha contado con la colaboración de un despacho de arquitectos y otro de ingenieros (Arquitectura B01 y Aiguasol) no ha requerido la aprobación de ningún plan especial ni la modificación del planeamiento urbanístico general, habiéndose realizado en el marco de las obras de rehabilitación del nuevo mercado de la ciudad y de reurbanización de su entorno. Esta circunstancia resalta la oportunidad e idoneidad de los procesos de rehabilitación edificatoria y de regeneración y renovación urbanas, actuando como catalizadores del tránsito a un modelo urbano sostenible ambientalmente. En este sentido, el Considerando 19ํ de la Directiva 2018/844 establece que los estados deben fomentar, en los edificios nuevos y los sujetos a reformas importantes, instalaciones alternativas de alta eficiencia que proporcionen al mismo tiempo unas buenas condiciones climáticas interiores y la seguridad contra incendios y seísmos, de conformidad con las normas de seguridad nacionales.

El ámbito de actuación abarca una superficie de 40.000 m2 que incluye, en una primera fase, cinco edificios de titularidad pública -los cuales albergan dos superficies comerciales-69 a los que se añadirán dos más en una segunda fase.

68 El anuncio de licitación se publicó en el DOG núm. 6578 de 3 de marzo de 2014, en el BOP núm. 48 del 11 de marzo de 2014 y en el perfil del contratante del Ayuntamiento.

69 La UE ha allanado el camino a las operaciones que promuevan una gestión eficiente de las instalaciones para garantizar un mínimo gasto energético cuando sean acometidas por el sector público. Hasta ahora, el coste de la inversión inicial en eficiencia energética en edificios públicos se consideraba como gasto, pero la Comisión Europea ha introducido mayor flexibilidad en las normas de contabilización de los contratos de rendimiento energético en las cuentas públicas para permitir que no computen por este concepto. Así, los contratos de rendimiento energético en los que la eficiencia energética se obtiene con medidas de gestión de la energía (sin inversión en equipos suplementarios o renovación) se consideran simples contratos de servicios 0 mantenimiento. Sobre el modo de consignar los contratos de rendimiento energético, vid. EUROSTAT, Eurostat Guidance Note. The recording of Energy Performance Contracts in Government Accounts, 19 de septiembre de 2017. En línea:

http://ec.europa.eu/eurostat/documents/1015035/7959867/Eurostat-Guidance-Note-RecordingEnergy-Perform-Contracts-Gov-Accounts.pdf/ (última consulta: 11 de mayo de 2018). 
${ }^{70}$ La iniciativa la promueve el Ayuntamiento de Olot y la UTE Gas Natural-Wattia Innova.

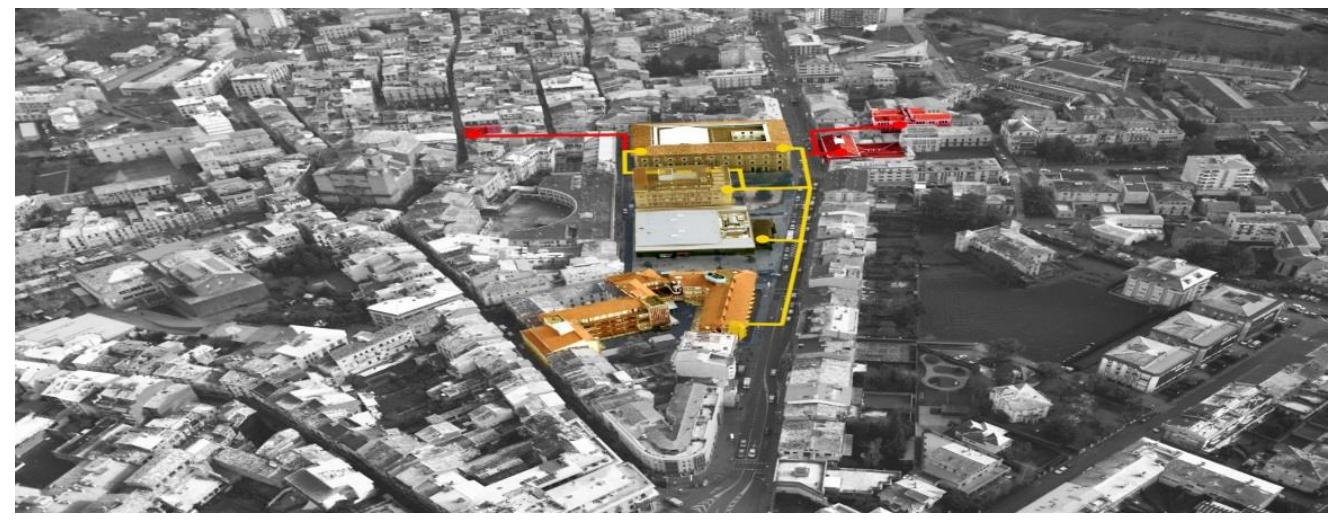

Figura 1.- Ámbito de actuación de la Xarxa Espavilada en el centro de Olot. Fuente: Wattia.

Mediante la aplicación de idéntico know how que en EspaiZero, se implementa por vez primera en el país un District Heating and Cooling con un modelo de producción centralizada de energía de $\mathrm{Km} 0$ que emplea un alto componente de domótica. Siguiendo la iniciativa primigenia, los edificios de la zona District satisfacen sus necesidades térmicas mediante una óptima combinación de energías renovables y un sistema inteligente de control automatizado. El sistema integra cuatro energías: las tres renovables (geotérmica, fotovoltaica y biomasa) y además una caldera de gas natural, que actúa como backup de la instalación, ${ }^{71}$ de manera que pueda garantizar la prestación del servicio en las puntas de incremento de la demanda, así como su continuidad en caso de complicaciones en el funcionamiento de las calderas de biomasa. La red de distrito es conocido como Xarxa Espavilada debido al alto componente tecnológico y de control utilizado: la tecnología punta es capaz de elegir la fuente de energía renovable más apropiada en cada momento y de trabajar aprovechando los sistemas de acumulación instalados. El sistema de control permite sincronizar la producción energética con la demanda existente teniendo en cuenta las predicciones climatológicas, merced a la integración en el sistema de una estación meteorológica que garantiza un pronóstico fidedigno.

\footnotetext{
${ }^{70} \mathrm{El}$ antiguo Hospital de Sant Jaume (actualmente ocupado por una residencia de la tercera edad y dos locales comerciales), las residencias geriátricas Montsacopa y La Caritat, el Museo Comarcal de la Garrotxa y el mercado municipal. Posteriormente, se añadirán el Casal de la Gent Gran y Can Monsà.

$71 \mathrm{Si}$ bien el gas natural es la fuente energética convencional, produce menos emisiones contaminantes que otros combustibles fósiles, como el carbón o el petróleo.
} 
La divulgación, así como la sensibilización y concienciación de la ciudadanía frente al cambio climático, son piezas clave del proyecto. Por este motivo, se decidió dar visibilidad a la sala de máquinas, denominada "Sala de las Energías", ubicándola en la planta baja del edificio del antiguo hospital, para que, a través de grandes ventanales, los transeúntes puedan observar el funcionamiento del sistema de producción energética.

La Sala se concibe además como un espacio pedagógico y participativo en el que se imparte formación en materia de eficiencia energética, medida que se ha complementado con la colocación de una pantalla informativa sobre la gestión de la central energética (consumo energético, tipo de energía que se está produciendo y distribuyendo en cada momento y emisiones de $\mathrm{CO} 2$ que gracias a esta red de producción no se emiten a la atmósfera). También se están llevando a cabo campañas de concienciación ciudadana (como "OlotRespira") que se utilizan como herramienta educativa para promover el uso de energías limpias.

\section{ii. Funcionamiento y optimización del sistema energético combinado}

El distrito funciona mediante un sistema inteligente que decide de forma anticipada el tipo de energía que va a utilizar en función de las condiciones meteorológicas. La elección también viene condicionada por aspectos económicos, como la tarifa eléctrica y el nivel de demanda de consumo de los edificios.

La Xarxa Espavilada se abastece mediante dos calderas de biomasa y una de gas natural, un sistema geotérmico y un sistema fotovoltaico. La red urbana de climatización de frío y calor del distrito tiene una longitud aproximada de 1.800 m2 y permite climatizar los 40.000 m2 de superficie de los edificios que están conectados a la misma. El sistema abastece de calor de alta temperatura, calor de baja temperatura y frío mediante dos redes: una que suministra calor a alta temperatura y otra que suministra los consumos de calor a baja temperatura y de frío, en invierno y verano, respectivamente. Como decíamos, la generación de energía se produce mediante tres fuentes renovables:

- Geotermia: Aprovechando las obras de rehabilitación del nuevo mercado, se construyeron 24 pozos de geotermia en el subsuelo de la plaza del 
mercado (con una longitud de intercambio de $2.400 \mathrm{ml}$ ) para generar calor de baja temperatura en invierno y frío en verano. En la "Sala de las Energías" se instalaron 2 acumuladores de agua caliente de 10.000 litros, 3 bombas geotérmicas de $60 \mathrm{~kW}$ (180 kW de potencia en total) y el sistema de impulsión y control de la red de suministro de energía.

- Biomasa: se instalaron dos calderas de biomasa, con una potencia total de $600 \mathrm{~kW}$ (450 kW y $150 \mathrm{~kW}$ ), que generan calor de alta temperatura.

- Solar fotovoltaica: En la cubierta del edificio Sant Jaume se instalaron placas fotovoltaicas, lo que permite que todo el sistema de bombeo de energía del distrito se alimente con energía solar. Las máquinas de refrigeración geotérmicas funcionan asimismo con energía fotovoltaica. La potencia instalada es de 28,4 kW, garantizando la alimentación directa de la sala de máquinas que genera frío y calor en modo autoconsumo. La

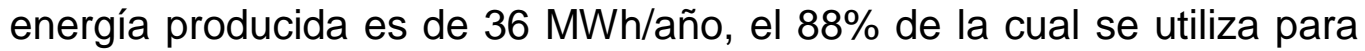
consumo propio y el $12 \%$ restante se destina a alimentar los bombeos de distribución de la red de distrito.

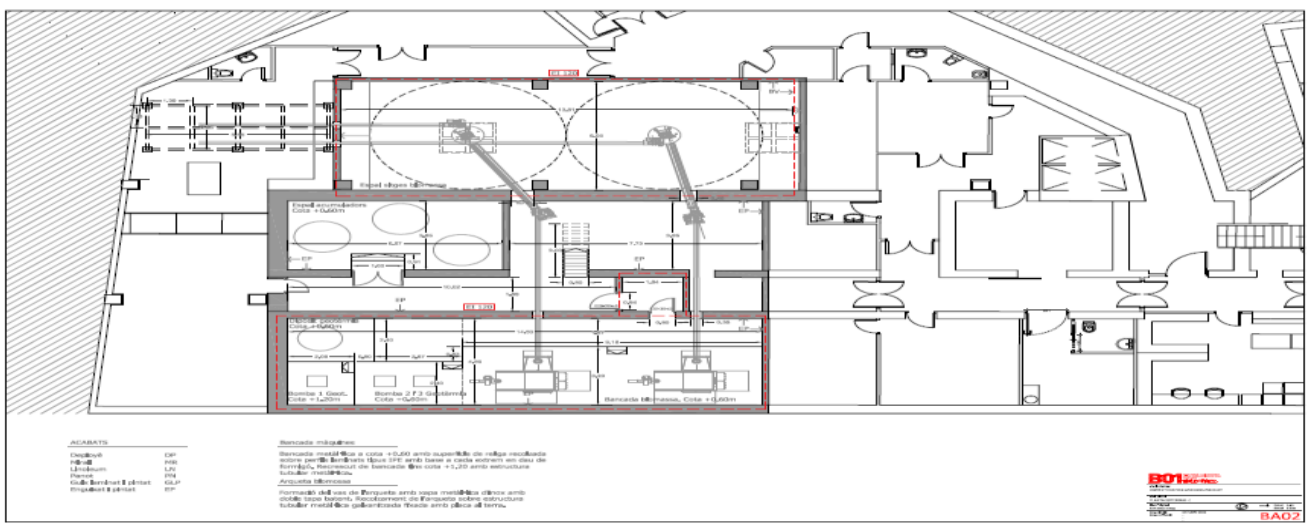

Figura 2.- Plano de implementación del proyecto. Fuente: Wattia

El ahorro energético y económico del proyecto es evidente. La solución combinada múltiple de fuentes de energía renovables permite ahorrar un $10 \%$ de la facturación energética (en comparación con el gasto que supondría el uso de fuentes de energía fósiles) y reducir en 750 t las emisiones a la atmósfera de $\mathrm{CO}^{7}{ }^{72}$

\footnotetext{
72 Entre las novedades que aporta esta central energética destacan: el doble uso de la tubería de frío para emitir calor a baja temperatura; el aprovechamiento del calor residual de la geotermia para la red de distrito en verano; la alta integración de sistemas para controlar cada elemento de producción y distribución maximizando la eficiencia energética global; y la gestión inteligente de
} 
El proyecto aprovecha las sinergias del territorio para garantizar la autosuficiencia productiva, aportando valor añadido a la cadena de generación energética. La mayor parte de la superficie de la comarca de La Garrotxa es forestal, con una elevada concentración de bosques (75\%), circunstancia que permite contar con una provisión de combustible de biomasa explotable de un máximo de 25.000 toneladas al año. Pero no solo se potencia un mercado local de biomasa km0. También se facilita la integración laboral de personas con discapacidad, en virtud de un acuerdo con una conocida cooperativa de productos lácteos de la comarca que emplea a personas con discapacidades intelectuales para que suministren biomasa procedente de la limpieza de los bosques de proximidad. Este aspecto del proyecto, la creación de un mercado local de biomasa, es una de las acciones de adaptación previstas en el Plan de Adaptación a los Impactos del Cambio Climático (2014), que da cuenta del progresivo abandono de la gestión forestal en la comarca y del incremento de la carga de combustible presente en los bosques, y propone el resurgimiento del sector a través de la producción de biomasa como fuente de energía renovable (p. 99). De esta manera, la Xarxa Espavilada acaba convirtiéndose en un ejemplo de cómo es posible aunar de forma inteligente, y alimentándose recíprocamente, objetivos de mitigación y de adaptación al cambio climático.

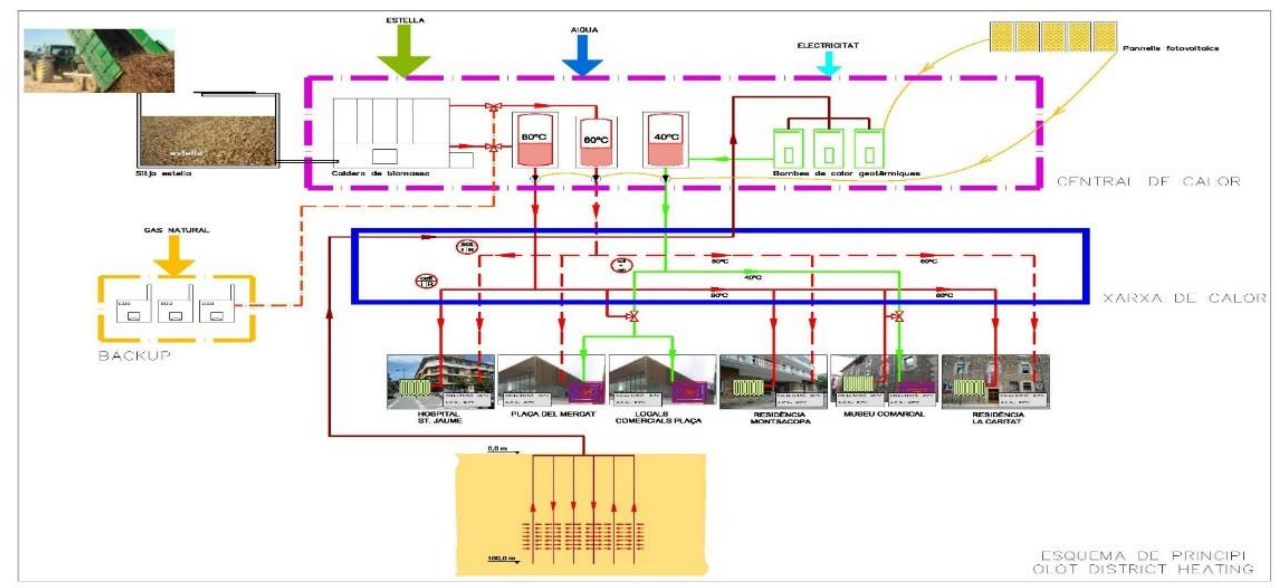

Figura 3.- Sistema de generación de energía. Fuente: SIGMA

\section{CONCLUSIONES}

las subestaciones para minimizar los consumos parásitos y optimizar el salto térmico en las mismas. "Red inteligente de energía de Olot. Proyecto de reconversión urbana con energías renovables con una gran vertiente social y ambiental", FuturEnergy, marzo de 2017, p. 49. 
La eficiencia energética es, junto con la reducción de emisiones y el fomento de las renovables, uno de los tres objetivos prioritarios de la política energética de la UE para el corto, medio y largo plazo. Estos objetivos deben permitir avanzar hacia una economía baja en carbono que garantice un sistema energético sostenible y competitivo, que asegure el abastecimiento, reduzca la dependencia externa y genere nuevas oportunidades de crecimiento económico. La eficiencia energética tiene por finalidad la reducción de los consumos y costes energéticos en todos los sectores de actividad económica, logrando un consumo racional y una reducción de la demanda mediante un mejor rendimiento de las instalaciones y sistemas técnicos del edificio. Según la International Energy Agency, las actuaciones e inversiones basadas en la optimización de la eficiencia energética son las que permitirán arrojar unos mayores logros en materia de reducción de emisiones de gases de efecto invernadero y la lucha contra el cambio climático.

Un edificio es eficiente cuando, manteniendo un mismo grado de confort, consume menos energía primaria exterior. Las iniciativas para aumentar la eficiencia energética del parque inmobiliario no solo tienen un impacto medioambiental, al reducir la factura energética, sino que estimulan la inversión y crean puestos de trabajo. Según datos de la UE, el sector de la edificación es responsable de casi la mitad del consumo total de energía en el conjunto del espacio comunitario. En noviembre de 2016, la Comisión Europea publicó el Paquete de Energía Limpia, en el que identifica al sector de los edificios como el mayor consumidor único de energía en Europa. Los edificios suponen el $40 \%$ de la demanda final de energía de la UE, más que ningún otro sector, pero también representan un gran potencial de ahorro energético y, una vez reformados y modernizados, pueden contribuir a la generación de energía extra de fuentes renovables o a proporcionar capacidad de almacenamiento de energía clave [Comunicación de la Comisión Europea, Acelerar la innovación en energías limpias, 2016]. En consecuencia, la participación de empresas constructoras y de servicios energéticos es esencial para satisfacer el objetivo de alcanzar una economía hipocarbónica. La construcción de nuevos edificios de bajo consumo energético o con consumos casi nulos constituye sin duda un reto para el sector, pero que duda cabe de que la verdadera tarea numantina será abordar la rehabilitación energética de un parque edificado que se caracteriza por su 
antigüedad, un estado de conservación deficiente y muy pocas concesiones a la eficiencia energética. Puesto que el $47 \%$ del parque inmobiliario español se construyó entre 1942 y 1981 -durante la vigencia de las normas técnicas que regulaban el sector (normas MV, 1957), que posteriormente se transformaron en las Normas Básicas de la Edificación (NBE), aprobadas por RD de 10 de junio de 1977-, es normal que sean una minoría los edificios que satisfacen los requisitos del CTE, en vigor desde 2006. Si bien es cierto que, en los últimos años, España ha experimentado una notable actividad en términos de rehabilitación (entre 2014 y 2016, el número de visados de dirección de obra para reforma y/o restauración se ha incrementado en un 12,8\%), el porcentaje de actuaciones rehabilitadoras se aleja de la media europea: los valores de renovación del parque residencial español se sitúan en el $0,8 \%$ frente al 1,82\% de Austria, el 1,75\% de Francia o el 1,49\% de Alemania (Actualización 2017. De la estrategia a largo plazo para la rehabilitación energética en el sector de la edificación en España, Ministerio de Fomento, p. 18). Es por ello, que las directivas comunitarias apelan reiteradamente a la contribución de este sector para recuperar la calidad y sostenibilidad del parque edificado mediante las actuaciones necesarias para conseguir el objetivo de ahorro energético (mejora energética de la envolvente y de las instalaciones de servicios, renovación de las instalaciones eléctricas, centralización de calderas, instalación de energías renovables, etc.).

Así pues, la rehabilitación de edificios existentes y las operaciones de regeneración y renovación urbanas para avanzar en la construcción de edificios de bajo consumo energético, seguramente más que las actividades de nueva construcción, son una buena oportunidad para reactivar el sector de la construcción pero también para impulsar el sector de los servicios energéticos, que se vislumbra como un negocio emergente con un elevado potencial de mercado, visto su protagonismo en los contratos de rendimiento energético. Aunque la eficiencia energética actúa en dos frentes: la arquitectura, diseño y ejecución del inmueble (compacidad, volumetría, orientación, materiales, aberturas, aislamientos, calidad de los cerramientos) y la calidad y funcionamiento de sus equipos energéticos, los dos sectores no han tenido hasta 
ahora excesiva relación ni sinergia entre ellos. ${ }^{73}$ No obstante, en adelante la rehabilitación edificatoria no podrá concebirse sin su dimensión energética, aunque existe el convencimiento generalizado de que a día de hoy la rehabilitación energética no ha alcanzado los niveles de intervención esperados. Según datos del CES, 13,6 millones de viviendas no cumplen las exigencias mínimas de ahorro de energía; de ahí que no se pueda desaprovechar el considerable potencial de incremento del ahorro de energía que tiene nuestro parque inmobiliario residencial y no residencial. Más allá de las competencias que tienen reconocidas el Estado y las comunidades autónomas, son los gobiernos locales los que, mediante el diseño de políticas de renovación urbanística del medio urbano, pueden lograr el objetivo de un parque inmobiliario descarbonizado, facilitando la transformación de los edificios existentes en edificios de consumo de energía casi nulo.

La UE ha fijado como objetivo para 2020 un ahorro del $20 \%$ en el consumo de energía primaria, con un aumento correlativo del consumo de renovables (Directiva "Triple 20"), un objetivo posteriormente replicado en la Directiva 2012/27/UE. Tomando como base el paquete de medidas sobre clima y energía hasta 2020, la UE ha formulado el Marco sobre Clima y Energía para 2030, cuyos objetivos fundamentales, más exigentes, son la reducción de al menos el $40 \%$ de las emisiones de gases de efecto invernadero respecto de los niveles de 1990 (vinculante) así como el aseguramiento de un mínimo del $27 \%$ de cuota de energías renovables (vinculante) y un mínimo del $27 \%$ de mejora de la eficiencia energética (objetivo revisable en 2020). Lamentablemente, estamos lejos de cumplir con estos retos temporales. Las instancias europeas han reconocido que se está avanzando muy lentamente hacia el objetivo común de eficiencia energética y por ello son bienvenidas todas las iniciativas decididas que buscan aprovechar el potencial de ahorro energético en energías fósiles que representan

\footnotetext{
${ }^{73}$ El contexto del cambio climático obliga a los dos sectores a trabajar codo con codo superando clichés como el de considerar que "la inversión en nuevas tecnologías para la promoción de la eficiencia energética en los edificios supone un aumento de los costes que encarecería el proceso de construcción y reduciría el margen de beneficio del promotor, que preferirá quedar estancado en las tradicionales instalaciones eléctricas y gasísticas en detrimento del uso de instalaciones de energía renovable" (García Montoro, 2016: p. 270). Lo cierto es que rehabilitar un edificio supone un ahorro energético del $60 \%$ frente a la construcción de otro nuevo dado que el coste energético de fabricación es muy elevado además del añadido de otros costes económicos y sociales como los derivados de un desalojo y realojo temporal de los propietarios actuales de los inmuebles (González Bustos, 2017b: p. 352).
} 
las intervenciones de eficiencia energética en los edificios públicos y privados. La Xarxa Espavilada de Olot es un ejemplo de iniciativa que impulsa un proceso de consumo energético eficiente, optimizando la demanda de la instalación. El nivel de eficiencia energética de los edificios que forman parte del ámbito de actuación es muy alto (edificios de consumo energético casi nulo), puesto que la cantidad de energía requerida se cubre en muy amplia medida con energía procedente de fuentes renovables producida en el entorno. Sus beneficios se extienden asimismo a aspectos económicos, sociales y medioambientales, puesto que la iniciativa ayuda a consolidar un mercado de los servicios energéticos que pueda asegurar la disponibilidad tanto de la demanda como de la oferta de dichos servicios, garantiza la integridad laboral de trabajadores discapacitados y fomenta la gestión forestal del territorio y la provisión de combustible de proximidad.

La reciente aprobación de la Directiva 2018/844, que modifica las directivas 2010/31/UE de eficiencia energética de los edificios y 2012/27/UE de eficiencia energética, en aquellos aspectos que no han dado los resultados previstos, debería marcar un nuevo hito en el proceso de avanzar en la construcción de edificios más inteligentes y energéticamente eficientes en pos de la instauración de una economía basada en bajas emisiones de carbono para 2050. La Directiva reitera las enormes posibilidades de mejora de eficiencia que ofrece el sector de la construcción (alrededor del $75 \%$ de los edificios son ineficientes desde el punto de vista energético), que continúa siendo el mayor consumidor de energía de Europa. En consecuencia, el principal objetivo de la propuesta de revisión es acelerar la renovación rentable de los edificios existentes a través de medidas como la integración de estrategias de renovación de edificios a largo plazo y la promoción del uso de tecnologías de la información y la comunicación y las tecnologías inteligentes a fin de garantizar el funcionamiento eficaz de los edificios.

\section{BIBLIOGRAFÍA}

Allende Landa, José, "Economía urbana sostenible, desarrollo urbano sostenible y crisis", en Federico A. Castillo Blanco (dir.), Claves para la sostenibilidad de ciudades y territorios, Aranzadi. Cizur Menor, 2014. 
Alonso de Armas, Isabel, "La Rehabilitación Eficiente de edificios en España ¿salvavidas de la obra nueva?”, en Revista de Obras Públicas, núm. 3591, 2017, p. 56-63.

Buildings Performance Institute Europe (BPIE), A snapshot of National Renovation Strategies. Examples from selected EU Member States. Briefing, 2017.

Buñuel, Miguel, "Los instrumentos económicos como incentivo a la eficiencia energética”, en Ramón Falcón y Tella (dir.), Estudios sobre fiscalidad de la energía y desarrollo sostenible, Instituto de Estudios Fiscales. Madrid, 2006.

Casado Casado, Lucía y Fuentes i Gasó, Josep Ramon, “Administración local: competencias sobre ecoeficiencia energética", en Fernando López Ramón (coord.), Observatorio de políticas ambientales 2016, CIEMAT/MINECO, 2016, p. 840-873.

Casares Marcos, Ana Belén, "Informe de evaluación de edificios y eficiencia energética”, Revista Jurídica de Castilla y León, núm. 39, 2016, p. 1-68.

Comisión de Expertos de Transición Energética, Análisis y propuestas para la descarbonización, Ministerio de Industria, Comercio y Turismo, 2018.

Contel Ballesteros, J. y Barrasa Shaw, J., "Real Decreto 235/2013 por el que se aprueba el procedimiento básico para la certificación de la eficiencia energética de los edificios", en El Consultor de los Ayuntamientos y de los Juzgados, núm. 9, 2013, p. 899-906.

Estrada Aliberas, Joan et al., "El fomento de las redes urbanas de frío y calor DHC- con fuentes de energía renovable. El proyecto europeo SmartReflex, conclusiones y experiencias en Cataluña", en Susana Galera Rodrigo y Mar Gómez Zamora (eds.), Políticas Locales de Clima y Energía: Teoría y Práctica, INAP, 2018, p. 499-529.

FEMP/Coordinación de Acción Territorial y Desarrollo Sostenible /Red Española de Ciudades por el Clima, La vulnerabilidad al cambio climático a escala local, FEMP. Madrid, 2010.

Fernández Artime, Rocío, "Eficiencia energética en la edificación”, en Beatriz Yolanda Moratilla Soria (coord.), Una década de análisis de las tecnologías 
energéticas, Asociación Nacional de Ingenieros del ICAI-Universidad Pontificia Comillas. Madrid, 2013, p. 63-80.

Fernández de Gatta Sánchez, Dionisio, "El Informe de Evaluación de los Edificios", en Tomás Quintana López (dir.), Urbanismo Sostenible. Rehabilitación, Regeneración y Renovación Urbanas, Tirant lo Blanch. Valencia, 2016, p. 370-425.

Galera Rodrigo, Susana, "Transición energética en España: retos jurídicos más allá del mercado", en Rafael Galán Vioque e Isabel González Ríos (dirs.), Derecho de las energías renovables y la eficiencia energética en el horizonte 2020, Instituto García Oviedo y Thomson Reuters-Aranzadi. Cizur Menor, 2017, p. $499-513$.

García Rubio, Fernando, "La contratación pública en materia de eficiencia energética. Un análisis de sus tipologías a la luz del TRLCSP, con especial referencia a la Administración local", en Fernando García Rubio y Lorenzo Mellado Ruíz (dirs.), Eficiencia energética y Derecho, Dykinson. Madrid, 2013, p. 93-175.

García Montoro, Lourdes, "Objetivo 2020: de la eficiencia energética a los edificios de consumo de energía casi nulo", en Revista CESCO de Derecho de Consumo, núm. 19, 2016, p. 263-271.

Gifreu Font, Judith, "El deber legal de conservación y rehabilitación de los propietarios de viviendas: la inspección técnica de edificios en Cataluña y la concreción del técnico facultativo competente para calificar el estado general de conservación”, en Práctica Urbanística, núm. 137, 2015, p. 96-116.

Gifreu Font, Judith, "Un cambio de rumbo en las políticas de suelo y urbanísticas: la mudanza del urbanismo expansivo y el redescubrimiento de la ciudad consolidada", en Cuadernos de Derecho Local, núm. 33, 2013, p. 30-55.

González Bustos, María Ángeles, "Eficiencia energética en la edificación", en Rafael Galán Vioque e Isabel González Ríos (dirs.), Derecho de las energías renovables y la eficiencia energética en el horizonte 2020, Instituto García Oviedo y Thomson Reuters-Aranzadi. Cizur Menor, 2017a, p. 249-266.

González Bustos, María Ángeles, "Marco regulador para la regeneración urbana", en Revista Vasca de Administración Pública, núm. 109, 2017b, p. 339359. 
González Ríos, Isabel, "Nuevos retos en materia de eficiencia energética en España tras el paquete energético de la UE de 2016", en Rafael Galán Vioque e Isabel González Ríos (dirs.), Derecho de las energías renovables y la eficiencia energética en el horizonte 2020, Instituto García Oviedo y Thomson ReutersAranzadi. Cizur Menor, 2017, p. 171-210.

González Ríos, Isabel y Ávila Rodríguez, Carmen María (coords.), Estudios sobre la normativa reguladora de la eficiencia energética. Especial referencia a su incidencia en las Administraciones públicas, Thomson Reuters-Aranzadi. Cizur Menor, 2016.

Institut Català d'Energia, Edificis de consum d'energia gairebé zero, Col-lecció Quadern Pràctic, Número 11, Generalitat de Catalunya. Barcelona, 2017. Institut Català d'Energia-ADHAC, Guía Básica de Redes de Distrito de Calor y de Frío, 2011.

Institute for Building Efficiency, Contrato de rendimiento energético en la Unión Europea: creación de definiciones, procesos y contratos "modelo" comunes, 2010.

Longo Martínez, Antonio Ángel, "Notas sobre la aplicación del Real Decreto 235/2013, de 5 de abril, por el que se aprueba el procedimiento básico para la certificación de la eficiencia energética de los edificios", en La Notaría, núm. 2, p. 88-93.

Loureda, Daniel, "Posibilidades de mejora de la eficiencia energética en los edificios ¿se hace lo necesario?”, en Revista de Obras Públicas, núm. 3591, 2017, p. 64-71.

Lucchi, Elena "Sostenibilidad y eficiencia energética de los edificios históricos", en Perspectivas. Revista PH, Instituto Andaluz del Patrimonio Histórico, núm. 88, 2015, p. 230-242.

Menéndez Rexach, Ángel, "Rehabilitación urbana y mejora de la eficiencia energética de los edificios. Una visión normativa", en Antonio Serrano Rodríguez (coord.), Ordenación del territorio, urbanismo y medio ambiente en un mundo en cambio, 2017, p. 171-201.

Ministerio de Energía, Turismo y Agenda Digital, Plan Nacional de Acción de Eficiencia Energética 2017-2020, 2017. 
Ministerio de Fomento, Estrategia a largo plazo para la rehabilitación energética en el sector de la edificación en España en desarrollo del artículo 4 de la Directiva 2012/27/UE, 2014.

Ministerio de Industria, Energía y Turismo - IDAE, Calificación de la eficiencia energética de los edificios, 2015.

Moreno Bau, Ángeles, "Relaciones internacionales en materia energética", en Cuadernos de Energía, núm. 38, 2013, p. 16-21.

Quintana López, Tomás, "Hacia un modelo de urbanismo sostenible" en Tomás Quintana López (dir.), Urbanismo sostenible. Rehabilitación, Regeneración y Renovación Urbanas, Tirant lo Blanch. Valencia, 2016, p. 15-70.

Renner, Michael, "Reducir la huella ambiental de los edificios", en La situación del mundo: informe anual del Worldwatch Institute sobre progreso hacia una sociedad sostenible (Ejemplar dedicado a: Ciudades sostenibles: del sueño a la acción), 2016, p. 165-187.

Román Márquez, Alejandro, "Eficiencia y ahorro energético en edificios e instalaciones públicas: los contratos de rendimiento energético", en Revista Andaluza de Administración Pública, núm. 97, 2017, p. 101-140.

Sandoval Fernández, Pablo, "La eficiencia energética en edificios: la implantación de las empresas de servicios energéticos en España", en Revista Aranzadi de Derecho Ambiental, núm. 20, 2011, p. 243-266.

Serra María-Tomé, Javier y Vega Catalán, José Luis, "Contexto actual: la UE, España y agentes motores de la sostenibilidad edificatoria", en Práctica Urbanística, núm. 145, 2017.

Serrano Lanzarote, B. y Sanchís Cuesta, A., "La Inspección Técnica de Edificios como herramienta de la mejora energética de la edificación existente", en Informes de la Construcción, vol. 67 (EXTRA-1), 2015, p. 1-9.

Strauss, Benjamin; Kulp, Scott y Levermann, Anders, Mapping choices. Carbon, climate and rising seas, our global legacy, Climate Central. Princeton, 2015.

Torres López, María Asunción (dir)., Administración local y energías renovables, Comares. Granada, 2015.

Villca Pozo, Milenka, "Incentivos fiscales para fomentar actuaciones de mejora en la eficiencia energética de viviendas de construcción antigua", en Revista Catalana de Dret Ambiental, vol. III (2), 2017, p. 1-22. 